University of San Diego

Digital USD

1986

\title{
A Comparative Study of the Attitude and Knowledge of Suicide between High School Students and High School Teachers
}

Karen Lee Clark EdD

University of San Diego

Follow this and additional works at: https://digital.sandiego.edu/dissertations

Part of the Leadership Studies Commons

\section{Digital USD Citation}

Lee Clark, Karen EdD, "A Comparative Study of the Attitude and Knowledge of Suicide between High School Students and High School Teachers" (1986). Dissertations. 487.

https://digital.sandiego.edu/dissertations/487

This Dissertation: Open Access is brought to you for free and open access by the Theses and Dissertations at Digital USD. It has been accepted for inclusion in Dissertations by an authorized administrator of Digital USD. For more information, please contact digital@sandiego.edu. 
A COMPARATIVE STUDY OF THE ATTITUDE AND KNOWLEDGE OF SUICIDE BETWEEN HIGH SCHOOL STUDENTS

AND HIGH SCHOOL TEACHERS

by

Karen Lee Clark

A dissertation submitted in partial fulfillment of the requirements for the degree of

Doctor of Education

1986

Dissertation Committee

William P. Foster, Ed.D., Director

Patricia Lowry, Ph.D.

Robert Nelson, Ph.D.

Michael Haney, Ph.D. 
To

Sonia, Christina, and Barbara

They have enriched my life

with their love, courage, and support.

AND

To

Chuck, in memory of him,

a child who left us too soon. 


\section{ACKNOWLEDGEMENTS}

The completion of this dissertation was not without credit to the many people who were such a valuable resource.

I am grateful to Dr. William Foster for his direction and willingness to support a quantitative dissertation which remained true to a qualitative spirit. In addition, I am grateful to Dr. Patricia Lowry for her sensitive input and caring heart. Dr. Nelson, I thank you for your sincere direction and loyalty to my cause. Finally, I thank you, Dr. Michael Haney, for your input and support. I also wish to thank $\mathrm{Dr}$. Joe Rost, who taught me what the true meaning of leadership is all about.

A special thanks to my secretary and friend, Bonnie, who assisted in the editing of my dissertation and kept my spirits intact. My special regards to the superintendents of the school districts who participated in my research and the governing boards who approved this study. Also, I wish to thank the San Diego County Office of Education for its support. In addition, I wish to thank the principals of the high schools for their assistance. I am most grateful to the high school teachers and students who gave of their time in responding to this very sensitive study.

To my staff at James Dukes Elementary School, I thank 
you for your encouraging words and dedication to children.

I wish to thank my parents, Bud and Lennie, who have remained loving and supporting throughout my entire personal and professional career, and who have never forgotten that I was their child. Lastly, I wish to thank my grandfather, who held me when I was young and never forgot to Iisten. 


$$
\text { - a secondary school should achieve more than }
$$

not driving its pupils to suicide. It should give them

a desire to live and should offer them support and backing

at a time in life at which the conditions of their

development compel them to relax their ties with their

parental home and their family. It seems to be indisputable

that schools fail in this, and in many respects, fall short

of their duty to providing a substitute for the family and

a rousing interest in life and the world outside. This is not a suitable occasion for a criticism for secondary

schools and their present shape; but perhaps I may emphasize

a single point. The school must never forget it has

to deal with immature individuals who cannot be denied

a right to linger at certain stages of their deveiopment

and even at certain disagreeable ones. 
TABLE OF CONTENTS

\section{CHAPTER 1}

INTRODUCTION . . . . . . . . . . . . . . . . . 1

STATEMENT OF THE PROBLEM . . . . . . . . . . . . . . 2

RESEARCH QUESTIONS . . . . . . . . . . . . 3

ASSUMPTIONS OF THE STUDY . . . . . . . . . . . . 7

HYPOTHESES . . . . . . . . . . . . . . . . . 7

DEFINITION OF TERMS . . . . . . . . . . . . . . . . 12

DELIMITATIONS AND LIMITATIONS . . . . . . . . . . 13

CHAPTER 2

INTRODUCTION . . . . . . . . . . . . . . . . 14

HISTORY OF SUICIDE . . . . . . . . . . . . . . . . . . 14

INVESTIGATIONS RELATED TO

ADOLESCENT SUICIDE . . . . . . . . . . . . . . 17

ANALYSIS OF THEORIES . . . . . . . . . . . . . 27

UNRESOLVED ISSUES . . . . . . . . . . . . . . . . . 31

\section{CHAPTER 3}

INTRODUCTION . . . . . . . . . . . . . . . 35

DESIGN, TIME PERIOD, AND

EXECUTION PLAN . . . . . . . . . . . . . . . . 35

CHAPTER 4

RESULTS . . . . . . . . . . . . . . . . . . . . 41

vi

Reproduced with permission of the copyright owner. Further reproduction prohibited without permission. 
Demographic Data . . . . . . . . . . . . 41

Analyses of the Subscores . . . . . . . . . . . 44

Acceptability and Normality of Suicide . . . . . 44

Mental and Moral Illness . . . . . . . . . . 47

Semi-Seriousness of Suicide . . . . . . . . 48

Religion Subscale . . . . . . . . . . 51

Risk of Suicide . . . . . . . . . . . . . 53

Lethality of Suicide . . . . . . . . . . . 55

Normality of Suicide . . . . . . . . . . . . 55

Irreversibility of Suicide . . . . . . . . . . 58

Demographic Aspects . . . . . . . . . . 59

Aging and Suicide . . . . . . . . . . . . 62

Motivation for Suicide . . . . . . . . . . 64

Impulsivity and Suicide . . . . . . . . . 66

Getting Even . . . . . . . . . . . . 67

Individual Aspects of Suicide . . . . . . . . 70

Sensation Seeking Attitudes of Suicide . . . . . 70

Related Analyses . . . . . . . . . . . . 72

Summary . . . . . . . . . . . . . . . . . 77

\section{CHAPTER 5}

SUMMARY, CONCLUSIONS, AND RECOMMENDATIONS • . . . . 78

Summary of the Purpose of the Study

and Review of the Literature . . . . . . . . 78

Conclusions Regarding Objectives

and Hypotheses . . . . . . . . . . . . 81

vii

Reproduced with permission of the copyright owner. Further reproduction prohibited without permission. 
Implications of Findings . . . . . . . . . . . 83

Recommendations for Further Research . . . . . . . 94

Summary . . . . . . . . . . . . . . . 95

REFERENCES . . . . . . . . . . . . . . . 96

viii 


\section{LIST OF TABLES}

Table 1 - Crosstabulation of Students and

Teachers Across Public and

Private Schools . . . . . . . . . .

Table 2 - Crosstabulation of Males and Females

Across the Four Grade Levels . . . . . . . 43

Table 3 - Crosstabulation of the Ages

of the Teachers by Sex . . . . . . . . 44

Table 4 - Crosstabulation of the Type

of School by Type of Class . . . . . .

Table 5 - Means on the Acceptability and

Normality Subscale for Teachers

and Students and for Public

and Private Schools . . . . . . . .

Table 6 - Analysis of Variance for Acceptability

and Normality Subscale Comparing

Roles and School Type . . . . . . . .

Table 7 - Means of the Mental and Moral IlIness

Subscale for Teachers and Students

and for Public and Private Schools . . . . 49

Table 8 - Analysis of Variance Comparing Roles

and Types of Schools on Mental

and Moral Illness of Suicide . . . . . 
Table 9 - Means for the Semi-Serious Subscale for the Teachers and Students and for the Public and Private Schools . . . . 50 Table 10 - Analysis of Variance Comparing the Roles and Types of Schools for the Semi-Serious Subscale . . . . . . . 50

Table 11 - Means on the Religion Subtest for Teachers and Students and for Types of Schools . . . . . . . . . .

Table 12 - Analysis of Variance for the Religion Subtest Comparing Roles and Types of Schools . . . . . . . . . 52

Table 13 - Mean Scores on the Risk of Suicide Subscale for the Students and Teachers and for the Types of Schools . . . . . . . . . . . .

Table 14 - Analysis of Variance for the Risk of Suicide Subscale Comparing the Roles and Types of Schools . . . . . . . . 54 Table 15 - Means for the Lethality Subscale for the Students and Teachers and for the Types of Schools . . . . . . . . 56

Table 16 - Analysis of Variance for the Lethality Subscale Comparing Roles and Types of Schools . . . . . . . . . 56 
Table 17 - Means on the Normality of Suicide Subscale for the Students and Teachers and for the Types of Schools . . . . . . . 57

Table 18 - Analysis of Variance for the Normality of Suicide Subscale Comparing Roles and Types of Schools with Simple Main Effects Comparisons . . . . . . . . 58 Table 19 - Means on the Irreversibility of Suicide Subscale for the Students and Teachers and for the Types of Schools ............... 60

Table 20 - Analysis of Variance for the Irreversibility of Suicide Subscale Comparing Roles and Types of Schools . . . 60

Table 21 - Means on the Demographic Aspects of

Suicide Subtest for the Students and

Teachers and for the Types of

Schools . . . . . . . . . . . . .

Table 22 - Analysis of Variance for the Demographic Aspects of Suicide

Subtest Comparing the Roles and Types of Schools . . . . . . . . . . 61

Table 23 - Means on the Aging and Suicide Subscale for the Students and Teachers and for the Types of Schools . . . . . . 
Table 24 - Analysis of Variance for the Aging

and Suicide Subscale Comparing the

Roles and Types of Schools . . . . . . . 63

Table 25 - Means on the Motivation for Suicide

Subscale for the Students and Teachers

and for the Types of Schools . . . . . . 65

Table 26 - Analysis of Variance for the Motivation

for Suicide Subtest Comparing the

Roles and Types of Schools . . . . . . 65

Table 27 - Means for the Impulsivity and Suicide

Subscale for the Students and

Teachers and for the Types of

Schools . . . . . . . . . . . 67

Table 28 - Analysis of Variance for the Impulsivity

and Suicide Subscale Comparing the

Roles and Types of Schools with

Simple Main Effects Comparisons . . . . . 68

Table 29 - Means on the Getting Even Subscale for

the Students and Teachers and for

the Types of Schools . . . . . . . . 69

Table 30 - Analysis of Variance for the Getting

Even Subscale Comparing Roles and

Types of Schools . . . . . . . . . 69

Table 31 - Means on the Individual Aspects of

Suicide Subscale for the Students and

Teachers and for the Types of Schools . . . 71

xii

Reproduced with permission of the copyright owner. Further reproduction prohibited without permission. 
Table 32 - Analysis of Variance for the

Individual Aspects Subscale Scores

Comparing Roles and Types of Schools . . . . 71

Table 33 - Means on the Sensation Seeking

Attitudes Subscale for the Students

and Teachers and for the Types of

Schools ............... 73

Table 34 - Analysis of Variance for the Sensation

Seeking Attitudes Subscale Comparing

Roles and Types of Schools . . . . . . . 73

Table 35 - Means for the Attitudes Toward Suicide

Subscale for the Students and Teachers

and for the Types of Schools . . . . . . 75

Table 36 - Analysis of Variance for the Attitudes

Toward Suicide Subscale Comparing

Roles and Types of Schools . . . . . . . 75

Table 37 - Means on the Knowledge of Suicide

Subscale for the Students and Teachers

and for the Types of Schools . . . . . . 76

Table 38 - Analysis of Variance for the Knowledge

of Suicide Subscale Comparing Roles

and Types of Schools . . . . . . . . 76 


\section{LIST OF APPENDICES}

Appendix A - Letter to Superintendents . . . . . . 101

Appendix B - Letter to Parents . . . . . . . . . 104

Appendix C - "Suicide Opinion Questionnaire" . . . . 106 
A COMPARATIVE STUDY OF THE ATTITUDE AND KNOWLEDGE OF SUICIDE BETWEEN HIGH SCHOOL STUDENTS AND HIGH SCHOOL TEACHERS

The researcher in this study sought to examine the comparison of the attitude and knowledge of suicide of high school students with the attitude and knowledge of suicide of high school teachers. The investigation will yield resilts which will be utilized for the purpose of developing a greater understanding of the attitude of both populations. The results will be analyzed with the prospects of utilizing this information for the preparation and formulation of effective suicide prevention and intervention programs at high school campuses.

This study, which extended from November, 1985 through March, 1986, was conducted in four high schools in the County of San Diego in the State of California. The sample consisted of respondents from both public and private high schools. Sixty-four percent of the participants were students while $36 \%$ of the participants were teachers. Seventy-nine percent of the respondents came from public schools while $21 \%$ of the respondents came from a private Catholic high school.

The instrument used to gather data focused on attitude and knowledge issues related to suicide. This instrument, 
titled "Suicide Opinion Questionnaire," was developed by $\mathrm{Dr}$. George Domino, Ph.D., professor at the University of Arizona. With permission from this author, the researcher used this instrument to gather this important data.

Statistic procedures were applied to 30 null hypotheses by a two-way analysis of variance. Findings were significant in specific cases and resulted in a significant difference between teacher and student attitude and knowledge on issues related to suicide. The researcher concluded that the following subsections yielded significant results, and they include: (1) acceptability and normality, (2) mental and moral illness, (3) semi-serious, (4) risk, (5) demographics, (6) impulsivity, and (7) individual aspects.

The researcher concluded that there is a significant difference in some areas between the attitude and knowledge of high school students on issues related to suicide and attitude and knowledge of high school teachers on issues related to suicide. This finding provides for a fundamental understanding of the differences and an opportunity to begin to explore the differences for the purpose of possibly deveioping a prevention and intervention program to bridge the gap of discrepancy and unite the efforts in dealing with this sensitive issue. 
Chapter 1

\section{Introduction}

The rate of suicide has increased dramatically (McKenry, Ph.D., et al., 1982).

Perhaps one of the most perplexing and disturbing medical and social problems of today is that of suicidal behavior among the young. Almost 5,000 adolescents and young adults committed suicide in 1977--an average of 13 a day. The present adolescent suicide rate is about twice as high as ten years ago and three times as high as 20 years ago. Suicide is, in fact, the third leading cause of death among 15-24 year olds; only accidents and homicides account for more deaths. (p.266)

Ross (1984) suggests that with the impact of the rising suicide rate among youth and the publicity attendant to it, there has beev, in the last two years, a rising interest in and openness to school suicide prevention programs. For example, three state legislatures including (1) California, (2) Louisiana, and (3) Florida have mandated that schools incorporate suicide prevention programs into 
their curriculum. The California legislature appointed a committee whose job it is to develop school programs for statewide use.

Examples of the school based programs might be those in the Denver Cherry Creek system and the Houston system. These schools, using their own employees, developed and implemented programs that include the training of administrators, counselors, and teachers. Therefore, as educational leaders assume the responsibility for addressing this critical issue, it is essential that research is conducted for the purpose of providing meaningful data which will enhance the way in which the issue of adolescent suicide is addressed in the educational arena.

\section{Statement of the Problem}

The purpose of this study will be to compare the attitude and knowledge of suicide of high school students with the attitude and knowledge of suicide of high school teachers. This investigation will yield results which will be utilized for the purpose of developing a greater understanding of the attitude and knowledge of both populations. The results will be analyzed with the prospects of using this information for the preparation and formulation of effective suicide prevention and intervention programs at the high school level. 


\section{Research Questions}

This study will attempt to answer the following questions:

1. Is there a difference between the attitude and knowledge of high school students and high school teachers on issues related to the acceptability and normality of suicide?

2. Is there a difference between the attitude and knowledge of high school respondents at the private school site and the public school site on issues related to the acceptability and normality of suicide?

3. Is there a difference between the attitude and knowledge of high school students and high school teachers on issues related to suicide and mental and moral illness?

4. Is there a difference between the attitude and knowledge of high school respondents at the private school site and the public school site on issues related to suicide and mental and moral illness?

5. Is there a difference between the attitude and knowledge of high school students and high school teachers on issues related to suicide as semi-serious?

6. Is there a difference between the attitude and knowledge of high school respondents at the private school site and public school site on issues related to suicide as semi-serious? 
7. Is there a difference between the attitude and knowledge of high school students and high school teachers on issues related to suicide and religion?

8. Is there a difference between the attitude and knowledge of high school respondents at the private school site and public school site on issues related to suicide and religion?

9. Is there a difference between the attitude and knowledge of high school students and high school teachers on issues related to suicide and the risk of suicide?

10. Is there a difference between the attitude and knowledge of high school respondents at the private school site and public school site on issues related to the risk of suicide?

11. Is there a difference between the attitude and knowledge of high school students and high school teachers on issues related to suicide and the lethality of suicide?

12. Is there a difference between the attitude and knowledge of high school respondents at the private school site and public school site on issues related to suicide and the lethality of suicide?

13. Is there a difference between the attitude and knowledge of high school students and high school teachers on issues related to suicide and the normality of suicide?

14. Is there a difference between the attitude and knowledge of high school respondents at the private school 
site and public school site on issues related to suicide and the normality of suicide?

15. Is there a difference between the attitude and knowledge of high school students and high school teachers on issues related to suicide and the irreversibility of suicide?

16. Is there a difference between the attitude and knowledge of high school respondents at the private school site and public school site on issues related to suicide and the irreversibility of suicide?

17. Is there a difference between the attitude and knowledge of high school students and high school teachers on issues related to suicide and the demographic aspects?

18. Is there a difference between the attitude and knowledge of high school respondents at the private school site and public school site on issues related to suicide and the demographic aspects?

19. Is there a difference between the attitude and knowledge of high school students and high school teachers on issues related to suicide and aging?

20. Is there a difference between the attitude and knowledge of high school respondents at the private school site and public school site on issues related to suicide and aging?

21. Is there a difference between the attitude and knowledge of high school students and high school teachers 
on issues related to suicide and motivation?

22. Is there a difference between the attitude and knowledge of high school respondents at the private school site and the public school site on issues related to suicide and motivation?

23. Is there a difference between the attitude and knowledge of high school students and high school teachers on issues related to suicide and impulsivity?

24. Is there a difference between the attitude and knowledge of high school respondents at the private school site and public school site on issues related to suicide and impulsivity?

25. Is there a difference between the attitude and knowledge of high school students and the high school teachers on issues related to suicide and getting even?

26. Is there a difference between the attitude and knowledge of high school respondents at the private school site and public school site on issues related to suicide and getting even?

27. Is there a difference between the attitude and knowledge of high school students and high school teachers on issues related to suicide and individual aspects?

28. Is there a difference between the attitude and knowledge of high school respondents at the private school site and public school site on issues related to suicide and individual aspects? 
29. Is there a difference between the attitude and knowledge of high school students and high school teachers on issues related to suicide and sensation-seeking?

30. Is there a difference between the attitude and knowledge of high school respondents at the private school and public school site on issues related to suicide and sensation-seeking?

\section{Assumptions of the Study}

1. It is assumed that the students will participate in the study and demonstrate a sincere attempt to respond to the survey.

2. It is assumed that the teachers will participate in the study and demonstrate a sincere attempt to respond to the survey.

3. It is assumed that the survey will be completed by the participants without consultation with other participants.

Hypotheses

The following hypotheses will be addressed in this study:

1. There is no significant difference between the attitude and knowledge of high school students and high 
school teachers on issues related to the acceptability and normality of suicide.

2. There is no significant difference between the attitude and knowledge of high school respondents at the private school site and the public school site on issues related to the acceptability and normality of suicide.

3. There is no significant difference between the attitude and knowledge of high school students and high school teachers on issues related to suicide and mental and moral illness.

4. There is no significant difference between the attitude and knowledge of high school respondents at the private school site and the public school site on issues related to suicide and mental and moral illness.

5. There is no significant difference between the attitude and knowledge of high school students and high school teachers on issues related to suicide as semi-serious.

6. There is no significant difference between the attitude and knowledge of high school respondents at the private school site and public school site on issues related to suicide as semi-serious.

7. There is no significant difference between the attitude and knowledge of high school students and high school teachers on issues related to suicide and religion.

8. There is no significant difference between the attitude and knowledge of high school respondents at the 
private school site and public school site on issues related to suicide and religion.

9. There is no significant difference between the attitude and knowledge of high school students and high school teachers on issues related to suicide and the risk of suicide.

10. There is no significant difference between the attitude and knowledge of high school respondents at the private school site and public school site on issues related to the risk of suicide.

11. There is no significant difference between the attitude and knowledge of high school students and high school teachers on issues related to suicide and the lethality of suicide.

12. There is no significant difference between the attitude and knowledge of high school respondents at the private school site and public school site on issues related to suicide and the lethality of suicide.

13. There is no significant difference between the attitude and knowledge of high school students and high school teachers on issues related to suicide and the normality of suicide.

14. There is no significant difference between the attitude and knowledge of high school respondents at the private school site and the public school site on issues related to suicide and the normality of suicide. 
15. There is no significant difference between the attitude and knowledge of high school students and high school teachers on issues related to suicide and the irreversibility of suicide.

16. There is no significant difference between the attitude and knowledge of high school respondents at the private school site and public school site on issues related to suicide and the irreversibility of suicide.

17. There is no significant difference between the attitude and knowledge of high school students and high school teachers on issues related to suicide and the demographic aspects.

18. There is no significant difference between the attitude and knowledge of high school respondents at the private school site and public school site on issues related to suicide and the demographic aspects.

19. There is no significant difference between the attitude and knowledge of high school students and high school teachers on issues related to suicide and aging.

20. There is no significant difference between the attitude and knowledge of high school respondents at the private school site and public school site on issues related to suicide and aging.

21. There is no significant difference between the attitude and knowledge of high school students and high school teachers on issues related to suicide and motivation. 
22. There is no significant difference between the attitude and knowledge of high school respondents at the private school site and the public school site on issues related to suicide and motivation.

23. There is no significant difference between the attitude and knowledge of high school students and high school teachers on issues related to suicide and impulsivity.

24. There is no significant difference between the attitude and knowledge of high school respondents at the private school site and public school site on issues related to suicide and impulsivity.

25. There is no significant difference between the attitude and knowledge of high school students and high school teachers on issues related to suicide and getting even.

26. There is no significant difference between the attitude and knowledge of high school respondents at the private school site and public school site on issues related to suicide and getting even.

27. There is no significant difference between the attitude and knowledge of high school students and high school teachers on issues related to suicide and individual aspects.

28. There is no significant difference between the attitude and knowledge of high school respondents at the 
private school site and public school site on issues related to suicide and individual aspects.

29. There is no significant difference between the attitude and knowledge of high school students and high school teachers on issues related to suicide and sensationseeking.

30. There is no significant difference between the attitude and knowledge of high school respondents at the private school and public school site on issues related to suicide and sensation-seeking.

\section{Definition of Terms}

Davis (1983:81) offers the following definitions of terms:

Adolescence: the period from ages 15 to 24 .

Attempted suicide: an attempt to take one's own life voluntarily and intentionally.

Intervention: the treatment and care of suicidal crisis or suicidal problems.

Prevention: methods or ways of trying to keep suicidal behavior from occurring.

Suicidal: marked by an impulse to commit suicide.

Suicidal behavior: threatened suicide, attempted suicide, or committed suicide.

Prodromal clues: warning signals of potential suicidal 
behavior.

Domino (1982:261) offers the following definitions:

Mental and moral illness: As it relates to suicide:

suicide is evil, immoral act, and those who commit suicide are cowards, mentally ill, or trying to get sympathy.

Semi-serious: As it relates to suicide: while suicide is bad, it is not so serious and is perhaps a reflection of man's aggressive nature.

Delimitations and Limitations

Generalizability is a factor to consider in analyzing the results of this research as the instrument, "Suicide Opinion Questionnaire," is being administered to only 120 high school students and 120 high school teachers in the San Diego, North County area. The purpose of this approach is to specifically utilize the results for the development of suicide prevention and intervention programs at the respective school sites.

In addition, only one instrument is used for this research and it is quantitative in nature only.

The limitations of the study include the fact that the participants are all volunteers and this, in itself, represents a limitation. In addition, this topic of research is very sensitive in nature and the participants might hesitate to respond honestly to the instrument. 
Chapter 2

\section{Introduction}

The purpose of this chapter is to review pertinent literature on adolescent suicide and offer the following: (1) a brief history of suicide, (2) investigations related to adolescent suicide, (3) analysis of theories related to adolescent suicide, and (4) unresolved issues, significant problems, and unanswered questions about adolescent suicide which require investigation.

\section{History of Suicide}

Davis (1983) comments on the fact that suicide probably occurred before man began keeping written records, but that the first known documented case of suicide was recorded nearly 4,000 years ago. This Egyptian document known as "The Suicide" is dated sometime between 2000 and 1900 years B. C. (Hatton, Valente, and Rink, 1977). Some of the literature from this text is missing and thus open to a variety of interpretations, but Davis reports that some Egyptologists believe that this document accounts 
for the first incident of documented suicide.

Davis reviews the attitudes of primitive people toward suicide as she states:

A historical examination of the attitude of primitive people toward suicide reveals that suicide was looked upon in some cultures as a matter of course and was neither praised nor blamed. In other societies, suicide was highly censured; in yet other societies, suicide was considered courageous and honorable. (p.3)

From a historical viewpoint, the motivations for suicide of primitive people were similar to those of individuals who commit suicide today. Lublin (1963) addresses the following: "Revenge, a desire for reunion with a departed loved one, escape from pain or punishment or dishonor, a search for immortality" were motivations for suicide of primitive people (p.91).

In ancient Greek history and in the writings of Homer, suicide was viewed with admiration. The earliest suicide mentioned in Greek literature was that of Oedipus' mother, Jocasta, who was considered praiseworthy when she hanged herself after learning that she had been living with her son, the person who had murdered her husband (Alvarez, 1972; Hatton et al., 1977). Although earlier Greek philosophers opposed suicide, the later Greek and Roman philosophers took a more lenient attitude toward suicide 
(Davis). The proud, self-reliant, unbending nature of the Stoics was believed to have been sustained only because they considered suicide a rational refuge from extreme suffering and despair (Dublin, 1963).

Suicide continued through the first and second century with surprising frequency (Dublin, 1963), and it was not until the second Council of Brage, in A. D. 563, that suicide was condemned by the Catholic Church (Alvarez, 1972; Dublin, 1963; Hatton et al., 1977). During the Middle Ages, the incidence of suicide declined significantly.

In history there were defenders of suicide and, in particular, a representative from the Protestant religion, John Donne (1573-1631) attacked the attitude of the Church and suggested that suicide was neither a violation of the law or against reason (Davis:7). Hatton et al. (1977) observed that during the Eighteenth Century in France, Montaigne, Voltaire, and Rousseau criticized hostility toward suicide. William James (1842-1910), an American philosopher, believed that religion was a deterrent against suicide, but considered suicide a matter of individual choice (Dublin, 1963; Hatton et al., 1977).

Davis observes that the attitude toward suicide in America varies today. The Roman Catholic Church denies a person who culpably commits suicide the right to a Christian burial (p.7). Judaism frowns on suicide, and no 
branch of Judaism views suicide as an acceptable act. However, even the Jews committed suicide during Hitler's extermination program (Dublin, 1963).

In summary, suicide has been studied for many years, and it was not until the late 1950s that suicidology became the subject of intense scientific study (Davis, 1983:7). Davis notes that The Los Angeles Suicide Prevention Center was funded by the National Institute of Mental Health and it was opened in 1958 under the direction of two psychologists, Edwin S. Shneidman and Norman L. Farberow. The first national conference on suicidology was held in 1968, and following this conference, the American Association of Suicidology was formed.

\title{
Investigations Related to Adolescent Suicide
}

\begin{abstract}
Statistically an investigation of suicide is difficult due to the unreliability of the data (Miller, 1975:11). Peck et al. (1985) states that suicide is among the top three causes of death for persons under 24 years of age. Furthermore, he reports that it is believed by some suicidologists that many of the deaths registered as accidents are actually suicidal. This is true in one-car, one-driver accidents (p.5). Seiden (1984) reported that for 1980 the youthful suicide rate was 12.3 per 100,000 .
\end{abstract}


That is, in 1980 , there were 12.3 deaths by siicide for every 100,000 persons aged 15 to 24 . In real numbers this translates to more than 6,000 deaths by suicide among 15-24 year olds in the United States, as reported by the U. S. Department of Health, Education, and Welfare, 1980. Seiden (1984) suggests:

Yet these deaths are only the visible tip of the iceberg: (1) suicides tend to be underrecorded because of the social, legal, religious, and economic stigma that still attaches to selfdestruction; (2) there are many more nonfatal suicide attempts than suicide deaths among young people. (p.1)

Accordingly this means that youthful suicide attempts can be estimated as numbering somewhere between 35,000 and a quarter of a million cases annually (p.1). Over the past 20 years the United States' mortality rate has decreased for every age group except one: Americans aged 15 to 24 who now have a higher rate than 20 years ago (Seiden et al., 1980:195).

Teicher et al. (1981) conducted a study to describe and evaluate the significant events, depressive symptoms, and selected demographic variables associated with 108 adolescent suicide attempters. The data was collected over a two year period (September 1977-August 1979) from adolescents who were at Children's Hospital Emergency 
Room in Columbus, Ohio. Each adolescent suicide attempter was given a psychiatric evaluation, including a menial status examination, to determine suicidal intent and likelihood of repetition of the suicidal act. In addition, demographic and family background information were obtained (marital stability, socioeconomic status). Forty-nine percent of the adolescents were living at home with both parents at the time of the attempt. Twenty-nine percent were living at home with one parent, and eight percent were living with other relatives or friends. Fourteen percent resided in institutions. The findings of this investigation revealed a high incidence of parental divorce of adolescents who attempted suicide and this finding supported other findings which have revealed a family background of marital instability, marital unhappiness, disruption of residence, and inadequate parental functioning in suicidal adolescents (Corder et al., 1979; Jacobs, 1979; Schrut and Michaels, 1969; Seiden, 1974). Teicher et al. reported that the most frequently cited reason for suicidal attempts was parental problems (52 percent). Other reasons mentioned include problems with the opposite sex (30 percent) and school problems ( 30 percent).

Teicher et al. summarized their findings by reporting, commenting:

Precipitating events related to the adolescent suicide attempt must be evaluated within the 
context of the individual's social-psychological history. (p.91)

They also viewed adolescent suicide as a result of a progression of problems through three stages: (1) a long-standing history of problems, (2) a period of escalation and intensification of problems by the introduction of new problems associated with adolescence, and (3) a final state of a recent onslaught of problems usually characterized by a change in or desolution of any meaningful social relationship (p.91).

Teicher and Jacobs (1965) presented a paper at the 21st annual meeting of the American Psychiatric Association in New York. The paper dealt specifically with the conscious deliberations of the adolescents and the process by which they are led to conclude that death is the only possible solution to life's problems. The sample of their study which led to this presentation consisted of 68 adolescents between the ages of 14 and 18 years of age who were treated at the Los Angeles County General Hospital. for attempted suicide. The data resulting from this study represents findings related to 20 cases in the research series. Three-fourths of the patients were female and an average age of 16 . Sixty-two percent were white, 21 percent Negro, and 17 percent Mexican-American. The findings resulting from an analysis of the case studies determined that following a "long standing history of problems," 
there existed a stage of "escalation of problems" (p.125). In addition, 69 percent of all "behavioral problems" in which the adolescent who has attempted suicide reports he has engaged, according to his own account, began within the past five years. An interesting observation of the sample population in this study reveals the fact that about one-third of the adolescents who attempted suicide were not enrolled in school at the time of the attempt. Yet, none of these adolescents had dropped out because of poor scholarship (p.1256). Teicher et al. reports: Reasons for non-attendance in school were almost always events which contributed to the suicide attempt itself: prior suicide attempts, pregnancy, "behavioral problems" or institutionalization. (p.1256)

McIntire et al. (1971) examined early indicators of self-destructive behaviors in children and adolescents as a result of analyzing a survey conducted of Nebraska pediatricians' opinions and involvement with selfdestructive children and adolescents. In October of 1982, a questionnaire was sent by McIntire et al. to 110 physicians included in a current list of members of the Nebraska Chapter of the American Academy of Pediatrics. Items were chosen which addressed the following: (1) attitudes about management and referral practices concerning suicide at+empters, accident-prone children, and abusive or 
neglectful parents, (2) the perceived degree of risk associated with certain broadly chosen indicators of selfdestructive behaviors, (3) opinions concerning the relative effectiveness of a small sample of programs for suicide prevention, and (4) characteristics of the physicians, including age, sex, years of practice, proportion of time spent in practice, and population size of the community (p.260).

Questionnaires were returned by 65 pediatricians for a response rate of $59.1 \%$. The survey of these Nebraska pediatricians suggested that they are knowledgeable about and interested in self-destructive cases, but they do not consider themselves primarily responsible for prevention or management (p.562).

Motto (1282) reported on a study conducted with a sample of adolescents (aged 10 to 19) known to be at high risk for suicide by virtue of their admission to a hospital due to a depressive or suicidal state. For a five-year period, 1969-1974, persons were identified who were in any of nine psychiatric inpatient settings in San Francisco. Such persons were considered to represent a high risk suicidal population. Of 3005 persons who satisfied these criteria for admission to the study, 335 were aged 10 to 19 , of whom 213 were female and 122 were male.

In this sample of 122 males, it was determined that their ethnic background was primarily Caucasian, with 
blacks predominating in the nonwhite categories (p.30). An extensive interview was conducted with each subject. The authors of this study discovered two high risk items which imply that a suicide attempt preceded the clinical interview. "Clear communication of intent" and "help sought actively before attempt" were identified (p.37). Motto expressed both the hope and dismay in such a discovery:

It appears that ample notice of an impending suicidal action was given in these instances, but that the needs of these youngsters were greater than the available resources could meet. We are aware of how demanding and difficult suicidal youngsters can be and that too often such expressions as "wanting attention," "suicidal gesture," and "manipulative" are used in evaluating them. The $36 \%$ of the suicides in our sample who had clearly indicated their intent before completing the act, compares remarkably closely with the $40 \%$ reported by Sanborn et al. (1973) and $46 \%$ found by Shaffer (1974). (p.37)

In this study, the data suggested that in high-risk adolescent males, the history of a broken home is more closely associated with completed suicide than with no suicide. Alcohol and drug abuse were mentioned in 
discussions of adolescents who displayed "suicidal behavior," but the relationship with suicide was not statistically significant (p.40). The author did find that a history of prior suicidal behavior is a visible indicator of potential risk. In the sample, 8.8 percent of the subjects who reported no prior suicide attempts went on eventually to commit suicide, while 9.8 percent of the sample with a history of one or more attempts did so. This information does not reflect a statistically significant figure, but it does reflect a higher incident of suicides completed by previous attempters. Although Motto admits that his study did not reveal the results he had hoped for in order to determine "predictors of adolescent suicidal behavior," this study does reflect an attempt to further understand this incident. Of significance is his determination that adolescents had issued warning signs prior to suicidal attempts. McKenry et al. (1982) conducted a study in which 46 adolescent suicide attempters and their parents were compared with 46 adolescent nonattempters and their parents using various measures of family conflict, family cohesion, and parental maladaptive behavior. Data analysis indicated several significant differences between these two family groups in these dependent measures of family functioning, suggesting that the family milieu plays an important role in the etiology of adolescent suicidal behavior. The 
subjects for this study were 92 adolescents between the ages of 12 and 18. Forty-six subjects were admitted for attempted suicide during 1979 and 1980. A comparison group ccnsisted of 46 nonsuicidal adolescents, from the same emergency room (admitted for minor injuries). On intake, the adolescent and his/her family were administered a questionnaire by clinically trained interviewers. The adolescent suicide attempters were demographically very similar to the comparison group of nonattempter adolescents on several important dimensions. A series of one-way analyses of variance and chi-square analyses in the case of nominal data were performed.

The adolescent attempters presented a more negative view of their relationship with their parents as indicated by several significant relationships. The attempters were significantly more likely to view the time spent with their parents as less enjoyable and viewed their parents' marriage as less well adjusted than did the nonattempters. The attempters also indicated a significantly greater parental pressure to do well in school. In addition, the attempters expressed the view that their mothers were significantly less interested in them as compared to the nonattempters. These perceptions by the adolescents were reinforced by the data from both the mothers and fathers of the attempters. The parents of attempters also evidenced more maladaptive behaviors than 
did the parents of non-attempters. Fathers of the attempters were significantly more depressed than fathers of nonattempters and mothers of attempters were significantly more anxious than mothers of non-attempters.

Litman (1966) reported on a study of adolescent suicides in Los Angeles for a period of one year. The study showed that male suicides outnumbered the female by nearly three to one, and that the modes of death chosen by the male adolescents were more violent (p.36).

Domino et al. (1982) conducted a study designed to assess attitudes toward suicide, which could be utilized in studies of community attitudes and in the training of professional interventionists, to measure the impact of specific educational procedures and other research and applied endeavors (p.257). For this study an instrument entitled the "Suicide Opinion Questionnaire" (SOQ) was administered to a sample of 285 adults under conditions of anonymity. The sample consisted of graduate students in counseling psychology, medical personnel in three hospitals, housewives, firemen, mental health workers, secretarial staff, and visitors to a large shopping center.

The results revealed some rather interesting data. Eighteen percent of the respondents agreed that suicide is an acceptable means to end an incurable illness on one item of the questionnaire, while 95 percent of the same respondents agreed on a different question that people 
do not have the right to take their own lives. Ninetyseven percent of the respondents felt that those who commit suicide are cowards who cannot face life's challenges.

Seventy-one percent of the respondents agreed that a suicide attempt is a "cry for help," and 75 percent of the respondents agreed that relatives of the suicide victim usually had no idea of what was about to happen. Furthermore, this study revealed the fact that the respondents agreed that children from a large family are less likely to commit suicide as adults than single or only children, and 74 percent of the respondents agreed that the most frequent message in suicide notes is of loneliness (p.259).

Domino noted that there are numerous attitudinal scales on death, but that there appear to be few developed specifically for suicide (p.257). Domino developed the SOQ for this purpose and the SOQ attempts to identify the attitudes of the respondent toward suicide.

\section{Analysis of Theories}

Much controversy surrounds the etiology of suicide among the young (Tishler et al., 1982:404). In spite of the increased interest in the topic, there have been surprisingly few studies of suicidal attempts by adolescents. Tishler observes that some studies fail 
to distinguish adolescents from adults, and inconsistent definitions of "adolescence" are used (p.404).

Williams and Lyons (1976) note that youthful suicidal behavior cannot be fully understood without a careful consideration of family relationships. Mounting evidence indicates a relationship between attempted suicide and disorganization of the nuclear family, often extending over generations, yet the exact nature of these familial deficiencies has rarely been explicitly explored (p.404).

The psychotherapy of suicidal individuals is a troublesome problem (Kovacs et al., 1974:363). Kovacs observes that the reason given by a patient for his suicidal attempt may provide a promising point of entry for treatment. From his research Kovacs determined that the reasons most commoniy reported by patients for their suicidal attempts are easily categorized. He reports that some patients report that their goal was to give up and escape from Iife and to seek release: life is "simply too much" or "not worth living." Their inner mental or emotional distress is "intolerable"; they see "no way out" of their problematic situations and are "tired of fighting" (p.363).

Kovacs reported that further investigation revealed that suicide attempters hoped that the suicide attempt would bring back some emotionally important person, make others realize that psychiatric "help is needed," resolve some environmental problem, or help them "get to the 
hospital" as a temporary respite from their surroundings (p.364). Kovacs' final comment suggests that it is worthwhile to know whether the patient's goal is to manipulate others or to escape from life. The desire to manipulate, or to have temporary respite from the environment, implies the presence of some hope for a positive outcome. On the other hand, the goal to escape from life, to seek release in death, suggests that life is seen in a hopeless and negative fashion ( $p .364)$. Kovacs concludes by commenting that some type of social intervention is required if the hopelessness is based on reality factors.

Frederick (1980) investigated the theories surrounding statistical data which reveal that males continue to dominate in the number of suicides with respect to committed suicides in all age ranges, although females outnumber males as suicide attempters. The ratio is at least three to one (p.2). He also reported that in 1968 over three times as many males actually took their lives as females, but a decade later more than four times as many males completed the act. Nearly one-fifth of the total suicides in the country are completed yearly by persons under 25 years of age. This applies to both sexes, and, if the national data are broken down into ten-year age groups, those persons 15-24 years of age constitute the greatest number. Frederick also reports that suicide rates among the white population continue to exceed those of other 
racial groups (p.7).

One of the problems in diagnosing suicidal behavior in very young persons is that traditional depressive signs do not appear as frequently as they do among adults (Frederick, 1980:11). Instead, the younger the individual, the less likely the classical signs are to appear. Conduct disorders and inefficiency in school are likely to make feelings of depression. Youngsters are more likely to become agitated or irritable or react in a negative fashion or become involved in behavior which is troublesome to others (p.11). Once suicidal young persons are located and engaged in treatment, they can be helped very quickly in many instances, assuming that no deep-seated psychopathology is present (Peck, 1981).

Present trends indicate that the suicide rate will continue to rise markedly into the next century, unless a significant nationwide educational and intervention program is developed. This prediction is shown for the year 2005, based upon a trend analysis by Frederick (1980). This increase will be more than 100 percent for the combined sexes, as well as for males between the ages of 10 through 24 years (p.13). Especially dramatic increases will occur for males 20 through 24, where the increase will be 146 percent. Frederick remarks that these figures are relatively conservative, since the utilization of data going back more than two-and-one-half decades, when the 
current rise in suicide rates among young persons began, would result in even more dramatic figures (p.13).

Problems of unemployment and difficulties in the workplace are especially perplexing for young persons. The rise in the cost of higher education, along with the paucity of jobs when education is completed, contribute to continuing frustrations. Punishment or inadequate child-rearing practices comprise a common factor. Frederick observes that a newly found freedom and independence often brings with it more insecurity and frustrations than the young person had imagined possible (p.15). Frederick concludes by commenting that every suicidal comment, threat, or act should be taken seriously. It is better to err on the side of being overcautious than of not being cautious enough :

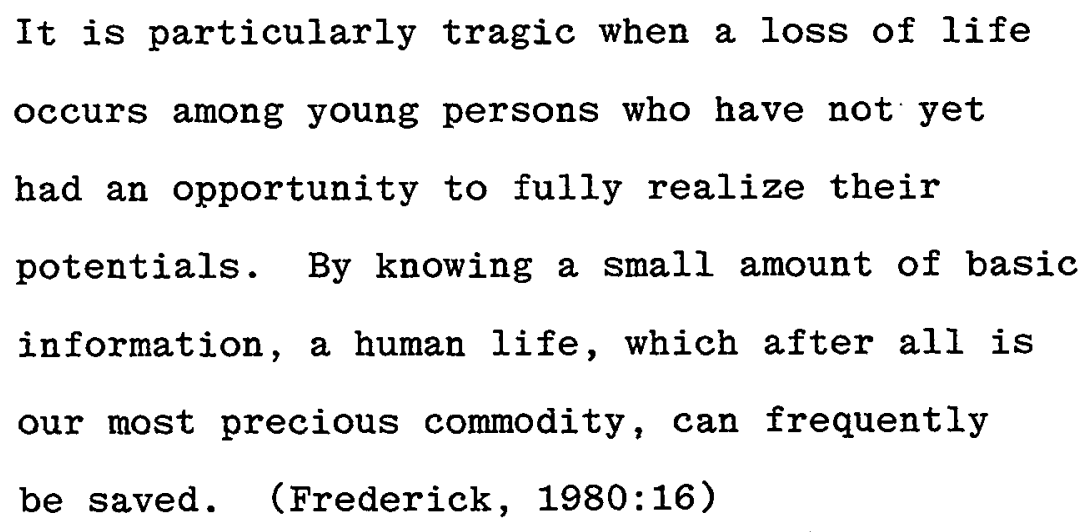

Unresolved Issues

Farberow (1983) observes that an alarm has been sounded 
regarding the increased rate in suicide among our young over the past two or three decades, an alarm which is both familiar and appropriate (p.191). He stresses that the concerns need to be widened, for it is not only in the United States that the increase has occurred, but it appears in other parts of the world as well.

The late 1970s and early 1980s have been characterized as the age of depression (Farberow, 1983:191). Depression has been the most frequently noted affect in presuicidal and suicidal young. Frederick (1983) asks the question, "Why do some persons seem to bear up under stress and others do not?" This remains as one of the unresolved issues of adolescent suicide.

An additional issue which remains in question is the fact that males commit suicide at such a higher rate than do females. Hatton et al. (1977) states that this behavior is considered to be consistent with the fact that it is more socially acceptable for females to asi for help and to communicate their fears and anxieties to those around them.

Finally, there is the issue of the continual increase in the rate of adolescent suicide. Why are so many young people taking their lives?

Farberow (1983:200) comments that, given any kind of choice, any mental health professional will choose prevention of suicide over treatment. He suggests: 
It is probably within the schools that most opportunity for primary prevention occurs. At adolescence, the peer group has attained an almost equal, if not paramount, role in influencing the behavior and attitudes of the students. It is highly possible to organize and conduct an effective and accepted program for suicide prevention in the schools. (p.201) Ross (1980) initiated a program for school personnel in 1976. She pioneered a program designed to train educators to participate in a suicide prevention program. She comments:

It is my conclusion that although some communities are concerned about prevention education programs in the schools, it does not constitute adequate grounds for neglecting an approach that can make a significant contribution in our efforts to prevent adolescent suicide. (1980:167)

The success of her program is currently being evaluated.

Farberow (1978:167) suggests the following:

Our primary source of hope seems to lie in increasing

our knowledge and skills which can be applied in education and mental health planning, and which will eventually lead to communities filled with concern and caring. Such intervention is necessary if we are to save our youth. 
Although unresolved issues have been addressed and remain a concern of this researcher, it is apparent to those individuals who have made a commitment to saving our youth that further studies and research which will assist in prevention and intervention programs will most certainly be worthwhile.

In summary, an intensive search in the area of research on adolescent suicide, including an ERIC search, revealed very little research conducted with the population being addressed in this dissertation study. It is the hope of this author that this timely research will not only prove to be a contributing factor in revealing data which can be applied toward the development of prevention and intervention programs, but it will also serve to encourage other researchers to pursue investigation into the incident of adolescent suicide. 
Chapter 3

Introduction

The purpose of this chapter was to describe the design, time period, and step-by-step execution plan of the study. In addition, the criteria for determining the validation and reliability of the data will be issued and evidence of the validity of the investigative procedures from other studies will be presented.

Design, Time Period

and Execution Plan

The objective of this research is to measure the knowledge and attitude of high school students on issues related to suicide and then compare these results with the knowledge and attitude of high school teachers on issues related to suicide. An additional objective was to compare the results of the high school students from a private Catholic high school with the results from high school students from public high schools. In addition, results from the study on high school teachers from the 
private Catholic high school was compared to the results from the study on high school teachers from the public high schools.

The description of the instrument used in this study was a 100 item questionnaire called the "Suicide Opinion Questionnaire" (SOQ) by its authors, Domino, Moore, Westlake, and Gibson (1980). The SOQ has been used to analyze factors involved in attitudes and knowledge toward suicide. The items on the SOQ extend beyond the positive-negative dimension. Respondents to the SOQ were instructed to give their honest opinion on each of trie items on a five-point response scale of Strongly Agree, Agree, Undecided, Disagree, and Strongly Disagree. In addition to the 100 items, there are six additional items that ask the sex of the respondent, whether the respondent is a teacher or a student, what the teacher teaches, what grades the high school students receive, the age of the teacher, and the grade level of the student.

Various areas of commonality are considered in 15 categories which are identified by Domino. They are: (1) acceptability and normality, (2) mental and moral illness, (3) suicide as semi-serious, (4) religion, (5) risk, (6) lethality, (7) normality, (8) irreversibility, (9) demographic aspects, (10) aging, (11) motivation, (12) impulsivity, (13) getting even, (14) individual aspects and (15) sensation-seeking (1982:259). 
The time period for considering the distribution of the survey and collection of data, including data analysis, was from January 12, 1986 to February 28, 1986.

The plan was executed in the following manner.

The primary step was to contact the respective school districts and notify the superintendents that it was the intent of the researcher to survey the students and teachers of the high schools, using the "Suicide Opinion Questionnaire." A letter of intent, a copy of the parent permission slip, and a copy of the SOQ were mailed to the school districts for approval prior to the initiation of the actual survey investigation. Following the approval of the high school districts, the high school principal at each high school, which total four high schools, was contacted. An appointment was made for the purpose of sharing the intent of the investigation as well as securing local school site permission to proceed with the research. After this appointment, a contact was made with a teacher who was appointed by the school site principal to assist in the distribution of parent permission slips to parents, survey instruments to students, and survey instruments to teachers for their completion. A total of sixty parent permission slips were delivered to the contact teachers and they, in turn, disseminated these slips to high school students. It was suggested by the researcher that equal numbers of students were selected at each grade level 
and teachers were selected from various disciplines who completed the survey instrument. It was emphasized to all parties concerned that participation in this research was voluntary and participation may terminate at any time that the respondent wished.

Following the completion of the survey exercise, the contact teacher at each school site contacted the researcher and the data was collected. At each school site, 30 students and 30 teachers were asked to complete the survey. The first students who had returned parent permission slips signed by their parents were asked to complete the survey. If fewer than 30 students or fewer than 30 teachers at each school site wished to complete the survey, data was collected from these surveys.

The data was collected from the survey instrument and a two-way anova was utilized which yielded the results. The outcome of the data analysis yielded an analysis of variance between teachers and students and between respondents at the public high school and the private high school. This strategy for analysis was justification for the use of a two-way anova.

The criteria used to determine whether the data was valid and reliable was derived from data provided by Domino. A careful and comprehensive survey of the literature on suicide was undertaken, and potentially useful items were typed individually on 3 " $\mathrm{x} 5$ " index cards. The survey yielded 
an initial pool of approximately 3,000 items. These items were analyzed carefully and duplicates, vaguely worded items, etc. were eliminated. Subsets of items were then read informally by a variety of judges, who included experienced crisis interventionists, psychologists who were working with suicidal patients, and graduate students in various disciplines. On the basis of their comments and reactions, a pool of 138 items was retained and administered to 96 college students twice, with a six week interval. The 100 items with the highest test-retest reliabilities (all above .68) were kept as the final version of the "Suicide Opinion Questionnaire" (SOQ) (1982:257). Additional evidence of validity of the investigation procedures was established by Domino et al. (1982) when the survey was administered to college students. In addition, the instrument was used by Domino, Cohen, and Gonzales (1981) to compare Jewish and Christian attitudes toward suicide. The use of these professional judges established the construct validity of the instrument. In summary, the instrument was both valid and reliable and was useful as an appropriate instrument for this dissertation research. The data was used in answering the questions and responding to the hypotheses listed in Chapter I. Finally, the results of the research were utilized to possibly develop meaningful prevention and intervention suicide programs for high school students. 
The purpose of this research was not to identify potential suicide victims or predict suicide attempters, but it was to gather data which reflected attitudes and knowledge of respondents toward suicide. Information from each school site was not available per either number of suicide attempts or completions. 
Chapter 4

\section{Results}

This chapter is divided into four sections. The first section addresses the demographic characteristics of the sample. The second section presents the analyses for the scores for each subsection of the "Suicide Opinion Questionnaire." Each of these analyses also addresses the hypothesis appropriate to each subsection score. The third section presents other analyses which add to the understanding of the data. The last section is a summary of this chapter and an overview of the next chapter.

\section{Demographic Data}

This section contains the distributions of students and teachers across the demographic information obtained from the participants. Table 1 presents the first demographic information of the distribution of students and teachers across the public and private classrooms. As seen in this table, 78.1 percent of the respondents came from the public schools while 21.3 percent came from private. Nearly 64 percent of the participants were students while 36.1 percent were teachers. Further, there 
was no significant difference in the distribution of students and teachers across the types of schools (ChiSquare $=2.85, \mathrm{df}=1, \mathrm{p}>0.05)$.

Table 1

Crosstabulation of Students and Teachers

Across Public and Private Schools

School

\begin{tabular}{|c|c|c|c|}
\hline & & & \\
\hline & & Privale & Total \\
\hline
\end{tabular}

Role

1

2

Student

Teacher

Chi-Square

2.84520
1

2

Column

Total

D. F.

1
80

52

132

78.1
28

9

37

21.9

Significance

0.0916
108 63.9

61 36.1 169 100.0

The second crosstabulation presents the distribution of the male and female students across the four grade levels. It can be noted in Table 2 that there were only 30 percent of the groups that were freshmen or sophomores. Nearly 33 percent were juniors and 36 percent were seniors. Further, there was an equal distribution of the groups 
between the sexes (Chi-Square $=0.86, \mathrm{df}=3, \mathrm{p}>0.05)$.

Table 2

Crosstabulation of Males and Females

Across the Four Grade Levels

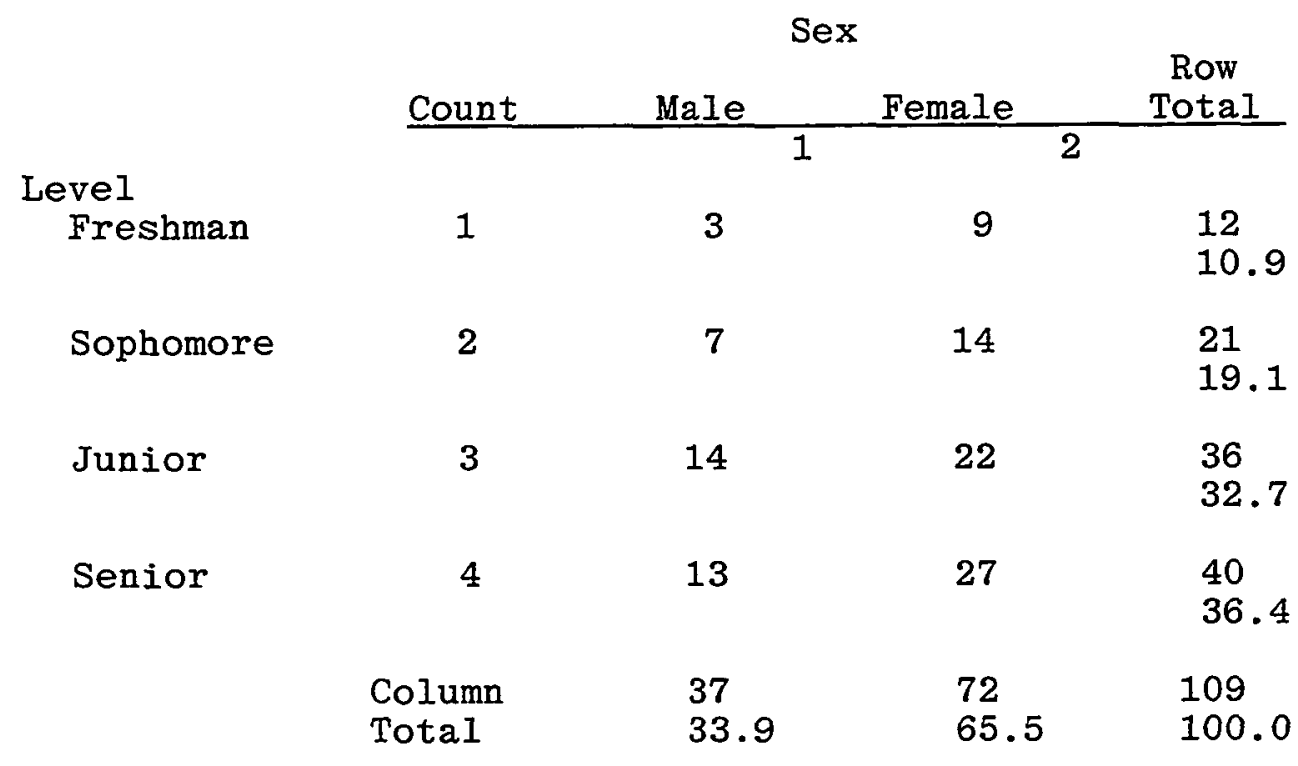

\section{Chi-Square}

0.86
D. F.

3
Significance

0.83

The ages of the teachers are crosstabulated with their sexes in Table 3. As can be seen in this table, there was no significant difference in the distribution of sex across the ages of the teachers (Chi-square $=1.37$, $\mathrm{df}=3, \mathrm{p}>0.05)$.

Reproduced with permission of the copyright owner. Further reproduction prohibited without permission. 
Table 3

Crosstabulation of the Ages

of the Teachers by Sex

\begin{tabular}{|c|c|c|c|c|c|c|c|}
\hline & & & & & & & \\
\hline & Count & $20-30$ & $30-40$ & $40-50$ & & $50-70$ & Total \\
\hline Sex & & & & & 3 & & $t$ \\
\hline Male & 1 & 4 & 16 & 7 & & 2 & $\begin{array}{l}29 \\
46.8\end{array}$ \\
\hline Female & 2 & 8 & 15 & 7 & & 3 & $\begin{array}{l}33 \\
53.2\end{array}$ \\
\hline & $\begin{array}{l}\text { Column } \\
\text { Total }\end{array}$ & $\begin{array}{l}12 \\
19.4\end{array}$ & $\begin{array}{l}31 \\
50.0\end{array}$ & $\begin{array}{l}14 \\
22.6\end{array}$ & & $\begin{array}{l}5 \\
8.0\end{array}$ & $\begin{array}{c}62 \\
100.0\end{array}$ \\
\hline Chi & uare & & F. & & $\underline{\text { Sig }}$ & snific & nce \\
\hline & & & & & & 0.73 & \\
\hline
\end{tabular}

The fourth table presents the distribution of the type of school (public or private) of the teachers by the classes they teach. As can be seen in this table, there were nearly equal numbers of public and private teachers in each of the types of classes (Chi-Square $=1.81, \mathrm{df}=4$, $\mathrm{p}>0.05)$.

Analyses of the Subscores

Acceptability and Normality of Suicide: The first analysis of variance compared the responses of students 
Table 4

Crosstabulation of the Type

of School by Type of Class

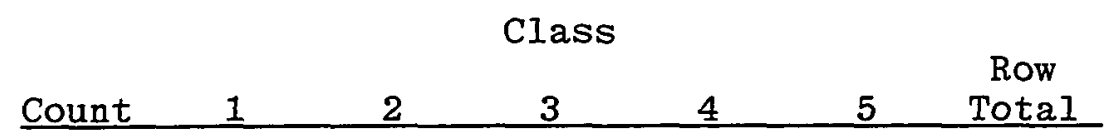

School

$\begin{array}{lccccccc}\text { Public } & 1 & 12 & 13 & 8 & 8 & 13 & 54 \\ & & & & & & & 85.7 \\ \text { Private } & 2 & 1 & 2 & 1 & 1 & 4 & 9 \\ & & & & & & & 14.3 \\ & \begin{array}{l}\text { Column } \\ \text { Total }\end{array} & 13 & 15 & 9 & 9 & 17 & 63 \\ & 20.6 & 23.8 & 14.3 & 14.3 & 27.0 & 100.0\end{array}$

Chi-Square

1.80707
D. F.

4
Significance

0.7712

and teachers to the subsection of the "Suicide Opinion Questionnaire" focusing on the acceptability and normality of suicide. The means of these two groups appears in Table 5. The analysis of variance for the data is presented in Table 6.

As can be seen in this table, there was a significant difference between students and teachers on this measure $(F[1,155]=17.57, p<0.001)$. There was also a significant difference between the type of school $(F[1,155]=6.30$, $\mathrm{p}(0.02)$. Finally, there was not a significant interaction 
Table 5

Means on the Acceptability and Normality

Subscale for Teachers and Students

and for Public and Private Schools

Types of Schools

public

Private

Roles

Students

25.34

22.89

AVERAGE

Teachers

29.74

26.00

24.68

AVERAGE

27.00

23.65

Table 6

Analysis of Variance for Acceptability

and Normality Subscale Comparing

Roles and School Type

Source of

Variation

Main Effects

Role

School

2-way Interaction

Sum of

Wean

Squares df Square

29.13

Explained

929.48

610.62

218.82

464.74

$\begin{array}{ll}1 & 610.62 \\ 1 & 218.82\end{array}$

$13.37 * *$

218.82

9.15

1

9.15

$6.29 *$

Residual

938.64

$3 \quad 312.88$

0.26

Total

5386.65

155

34.75

6325.29

158

40.03

$$
\begin{aligned}
* p & <0.02 \\
* * p & <0.001
\end{aligned}
$$


between the role of the participant and the type of school $(F[1,155]=0.26)$.

The significant difference between teacher and student indicates that the two groups significantly differed in their responses to this subsection. In terms of average scores, the students had a mean of 24.68 while the teachers averaged 29.13 , significantly higher. This means that the students saw suicide as more acceptable than did teachers. As a result of this difference, the first null hypothesis, which dealt with the differences of teachers and students on the acceptability and morality of suicide, is rejected.

The significant difference between types of schools indicates that public and private schools significantly differed in their responses to this subsection. On this subscale, the public school students averaged 27.00 while private school averaged 23.65. This indicates that the private school students scored significantly lower on this scale than the public school students did. Since there was a significant difference between public and private schools on acceptability and morality of suicide, the second null hypothesis is rejected.

Mental and Moral Illness: The means of the subgroups for this subscale appear in Table 7. The analysis of variance for the S. O. Q. subscale on mental and moral 
illness is presented in Table 8. As can be seen in this table, there was a significant difference between teachers and students on this measure $(F[1,158]=15.72, p<0.001)$. There was also no significant difference between types of schools $(F[1,158]=6.48, p>0.05)$ nor significant interaction $(F[1,158]=0.08, p>0.05)$.

Since there was a significant difference between teachers and students, examination of the means reflects that the students (mean $=23.02$ ) scored lower than the teachers (mean $=25.46)$. Further, since there was a significant difference on this subscale, the third null hypothesis is rejected. Finally, since there was no significant difference between public and private school teachers, the fourth null hypothesis, dealing with the acceptability and morality of suicide, is accepted.

Semi-Seriousness of Suicide: The next analysis addresses the performance of the participants on the semiSerious Subscale on the "Suicide Opinion Questionnaire." The means for the groups appear in Table 9. The analysis of variance for this subscale is presented in Table 10. As illustrated in this table, there was a significant difference between teachers and students on this scale $(F[1,160]=5.10, p<0.03)$. But there was no significant difference between type of schools $(F[1,160]=0.91$, p >0.05) nor was there a significant interaction $(F[1,160]=0.13, p(0.05)$. 
Table 7

Means of the Mental and Moral IIlness

Subscale for Teachers and Students

and for Public and Private Schools

Types of Schools

Public Private

$\begin{array}{lccc}\text { Roles } & & & \text { AVERAGE } \\ \text { Students } & 22.88 & 23.41 & 23.02 \\ \text { Teachers } & 25.40 & 25.78 & 25.46 \\ \text { AVERAGE } & 23.88 & 24.00 & \end{array}$

Table 8

Analysis of Variance Comparing Roles

and Types of Schools on Mental

and Moral Illness of Suicide

Source of

Variation

Main Effects

Role

School

2-way Interaction

Explained

Residual

Total

\begin{tabular}{|c|c|c|c|}
\hline $\begin{array}{l}\text { Sum of } \\
\text { Squares }\end{array}$ & $d f$ & $\begin{array}{l}\text { Mean } \\
\text { Square }\end{array}$ & F \\
\hline $\begin{array}{r}229.48 \\
229.08 \\
6.47\end{array}$ & $\begin{array}{l}2 \\
1 \\
1\end{array}$ & $\begin{array}{r}114.74 \\
229.08 \\
6.47\end{array}$ & $\begin{array}{r}7.87 \\
15.72 \\
0.44\end{array}$ \\
\hline 0.12 & 1 & 0.12 & 0.01 \\
\hline 229.60 & 3 & 76.53 & 5.25 \\
\hline 2302.00 & 158 & 14.57 & \\
\hline 2531.61 & 161 & 15.72 & \\
\hline
\end{tabular}


Table 9

$$
\begin{aligned}
& \text { Means for the Semi-Serious Subscale } \\
& \text { for the Teachers and Students and } \\
& \text { for the Public and Private Schools }
\end{aligned}
$$

Types of Schools

$$
\text { Public Private }
$$

$\begin{array}{lccc}\text { Roles } & & \text { AVERAGE } \\ \text { Students } & 15.25 & 15.79 & 15.39 \\ \text { Teachers } & 16.22 & 16.38 & 16.24 \\ \text { AVERAGE } & 15.63 & 15.92 & \end{array}$

Table 10

Analysis of Variance Comparing the Roles

and Types of Schools for the

Semi-Serious Subscale

\begin{tabular}{lrrrr}
$\begin{array}{l}\text { Source of } \\
\text { Variation }\end{array}$ & $\begin{array}{l}\text { Sum of } \\
\text { Squares }\end{array}$ & df & $\begin{array}{r}\text { Mean } \\
\text { Square }\end{array}$ & \multicolumn{1}{c}{ F } \\
\cline { 2 - 5 } & & & & \\
Main Effects & 32.48 & 2 & 16.24 & 2.74 \\
$\quad$ Role & 30.21 & 1 & 30.21 & $5.10^{*}$ \\
$\quad$ School & 5.39 & 1 & 5.39 & 0.91 \\
2-way Interaction & 0.74 & 1 & 0.74 & 0.12 \\
Explained & 33.22 & 3 & 11.07 & 1.87 \\
Residual & 947.52 & 160 & 5.92 & \\
Total & 980.75 & 163 & 6.01 & \\
$\quad * p<0.03$ & & & &
\end{tabular}


The mean for the students on this subscale was 15.39, significantly lower than that for teachers (mean $=16.24)$. Since there was a significant difference between students and teachers, the fifth null hypothesis, which focused on the semi-serious nature of suicide, was rejected.

The sixth null hypothesis stated that there would be no significant difference between public and private participants in their response to the semi-serious subscale of the "Suicide Opinion Questionnaire." Since there was no significant difference between these groups, the sixth null hypothesis is accepted.

Religion Subscale: The mean scores for the groups on the Religion subscale are shown in Table 11. Table 12 presents the anaiysis of variance for this subscale. As is illustrated in this table, there was no significant difference between teachers and students $(F[1,164]=$ $0.79, p>0.05)$. Three was no significant difference between the types of schools $(F[1,164]=0.73, p>0.05)$. Nor was there a significant interaction $(F[1,164]=0.09)$. The seventh hypothesis stated that there would be no significant difference between teachers and students on issues related to suicide and religion. Since there was no significant difference on this subscale for these two groups, the seventh null hypothesis is accepted. The eighth null hypothesis addressed the differences between 
Table 11

\author{
Means on the Religion Subtest \\ for Teachers and Students \\ and for Types of Schools
}

Types of Schools

Public Private

$\begin{array}{rccc}\text { Roles } & & & \text { AVERAGE } \\ \text { Students } & 17.61 & 17.18 & 17.50 \\ \text { Teachers } & 17.19 & 16.33 & 17.07 \\ \text { AVERAGE } & 17.44 & 16.97 & \end{array}$

Table 12

Analysis of Variance for the

Religion Subtest Comparing

Roles and Types of Schools

\begin{tabular}{lrrrr} 
Source of & \multicolumn{1}{c}{$\begin{array}{l}\text { Sum of } \\
\text { Squares }\end{array}$} & df & $\begin{array}{l}\text { Mean } \\
\text { Square }\end{array}$ & F \\
\cline { 2 - 5 } & 15.60 & 2 & 7.80 & 0.67 \\
Main Effects & 9.24 & 1 & 9.24 & 0.79 \\
$\quad$ Role & 8.43 & 1 & 8.43 & 0.72 \\
$\quad$ School & 1.03 & 1 & 1.03 & 0.09 \\
2-way Interaction & 16.64 & 3 & 5.54 & 0.47 \\
Explained & 1903.02 & 164 & 11.60 & \\
Residual & 1919.66 & 167 & 11.49 & \\
Total & & & &
\end{tabular}


types of schools on the religion subtest. Since there was no significant difference between the types of schools on this subtest, the eighth null hypothesis is accepted.

Risk of Suicide: The average performance of the groups is seen in Table 13 for the Risk of Suicide Subtest. The analysis of variance for this subtest is presented in Table 14. As is reflected in this table, there was a significant difference between students and teachers on this subscale $(F[1,165]=5.22, \mathrm{p}<0.03)$. However, there was no significant difference between types of schools $(F[1,165]=1.05, p>0.05)$ nor significant interaction $(F[1,165]=0.12)$.

The significant difference between students and teachers indicates that the students (mean $=12.44$ ) scored significantly lower than the teachers (mean $=13.13$ on this subscale. Since there was a significant difference between the two groups, the ninth null hypothesis, which addressed this difference, is rejected.

The lack of significant difference between the types of schools indicates that the public schools (mean $=12.79$ ) had a similar score to private schools (mean $=12.35)$. Since the two groups did not significantly differ on this subscale, the tenth null hypothesis, which focused on this difference, is accepted. 
Table 13

Mean Scores on the Risk of Suicide Subscale

for the Students and Teachers and

for the Types of Schools

Types of Schools

Public Private

Roles

AVERAGE

Students

12.55

12.14

12.44

Teachers

13.15

13.00

13.13

AVERAGE

12.79

12.35

Table 14

Analysis of Variance for the Risk

of Suicide Subscale Comparing

the Roles and Types of Schools

Source of

Variation

Main Effects

Role

School

2-way Interaction

Explained

Residual

Total

\begin{tabular}{|c|c|c|c|}
\hline $\begin{array}{l}\text { Sum of } \\
\text { Squares }\end{array}$ & $d i$ & $\begin{array}{l}\text { Mean } \\
\text { Square }\end{array}$ & $\underline{F}$ \\
\hline $\begin{array}{r}21.64 \\
16.13 \\
3.26\end{array}$ & $\begin{array}{l}2 \\
1 \\
1\end{array}$ & $\begin{array}{r}10.82 \\
16.13 \\
3.26\end{array}$ & $\begin{array}{l}3.50 * \\
5.22 * \\
1.05\end{array}$ \\
\hline 0.35 & 1 & 0.35 & 0.11 \\
\hline 22.00 & 3 & 7.33 & 2.37 \\
\hline 509.99 & 165 & 3.09 & \\
\hline 532.00 & 168 & 3.16 & \\
\hline
\end{tabular}

$* p<0.05$ 
Lethality of Suicide: The performance of the four groups on the Lethality of Suicide Subscale is summarized in Table 15. Table 16 contains the analysis of variance for this subscale for the different groups. As can be seen in this table, there was no significant difference between students and teachers on this subscale $(F[1,163]=$ $0.06, p>0.05)$. There was also no significant difference between the types of schools $(F[1,163]=0.46, p>0.05)$, nor significant interaction $(F[1,163]=1.57, p>0.05)$.

The eleventh null hypothesis stated that there would be no significant difference between students and teachers on their performance on the Lethality subscale of the "Suicide Opinion Questionnaire." Since there was no significant difference between the groups, the eleventb null hypothesis is accepted.

The twelfth null hypothesis stated that public and private schools would not significantly differ on this subscale. As reflected in Table 16, the two groups did not significantly differ. As a result, the twelfth null hypothesis is accepted.

Normality of Suicide: The means for the Normality of Suicide subscale appear in Table 17. The analysis of variance for this subscale is shown in Table 18. As can be seen on this table, there was no significant difference between students and teachers $(F[1,162]=0.75$, 
Table 15

\author{
Means for the Lethality Subscale for \\ the Students and Teachers and for \\ the Types of Schools
}

Types of Schools

Public Private

$\begin{array}{rccc}\text { Roles } & & & \text { AVERAGE } \\ \text { Students } & 9.51 & 9.54 & 9.51 \\ \text { Teachers } & 9.61 & 8.67 & 9.47 \\ \text { AVERAGE } & 9.55 & 9.32 & \end{array}$

Source of

Variation

Main Effects

Role

School

2-way Interaction

Explained

Residual

Total

\begin{tabular}{rrrr}
$\begin{array}{l}\text { Sum of } \\
\text { Squares }\end{array}$ & df & $\begin{array}{l}\text { Mean } \\
\text { Square }\end{array}$ & $F$ \\
\hline 1.62 & 2 & 0.81 & 0.24 \\
0.20 & 1 & 0.20 & 0.06 \\
1.53 & 1 & 1.53 & 0.45 \\
5.26 & 1 & 5.26 & 1.56 \\
6.88 & 3 & 2.29 & 0.68 \\
546.86 & 163 & 3.35 & \\
553.74 & 166 & 3.33 &
\end{tabular}


Table 17

\begin{abstract}
Means on the Normality of Suicide Subscale
for the Students and Teachers and

for the Types of Schools
\end{abstract}

Types of Schools

Public Private

Roles

AVERAGE

Students

16.30

15.57

16.11

Teachers

16.22

17.56

16.42

AVERAGE

16.27

16.05

p >0.05. Nor was there a significant difference between the performance of the schools $(F[1,162]=0.20, p>0.05)$. However, there was a significant interaction $(F[1,162]=$ $5.59, p(0.03)$. Since there was a significant interaction, a test of simple main effects was implemented and is a part of Table 18 .

As is reflected in this table, there was a significant difference between the teachers and students who were from the private $\operatorname{school}(F[1,162]=6.29, p>0.02)$. This means that the private school students (mean $=15.57)$ scored significantly lower than the private school teachers $($ mean $=17.56)$.

Since there was no significant difference between 
Table 18

\author{
Analysis of Vaxiance for the Normality of \\ Suicide Subscale Comparing Roles and \\ Types of Schools with Simple \\ Main Effects Comparisons
}

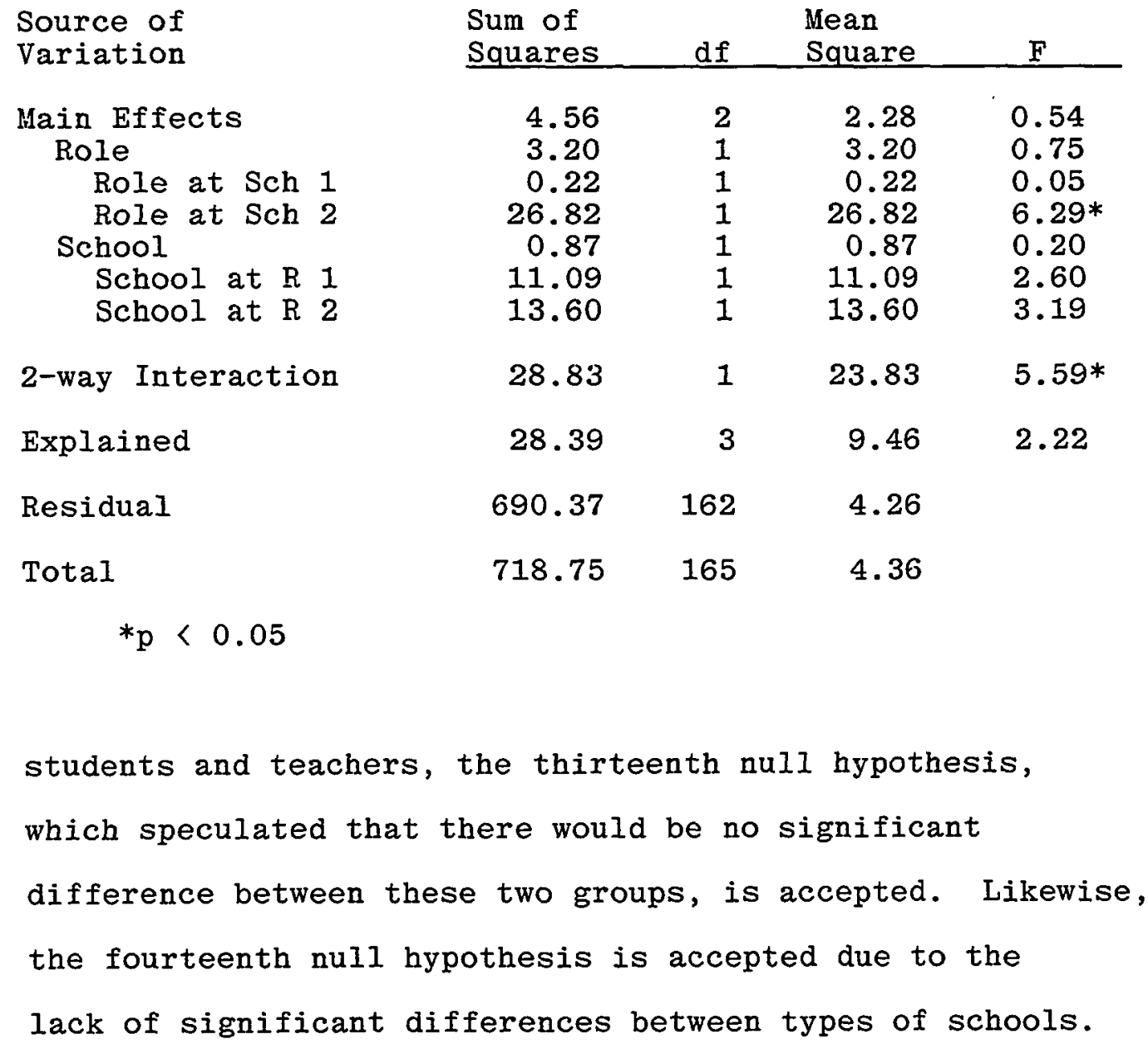

Irreversibility of Suicide: Table 19 presents the mean scores for the four groups on the Irreversibility 
of Suicide Subscale. The analysis of variance for this subscale is presented in Table 20. As is reflected in this table, there was no significant difference between students and teachers on this subscale $(F[1,164]=0.79$, p > 0.05). There was also no significant difference between types of schools $(F[1,164]=2.32, p>0.05)$ nor was there a significant interaction $(F[1,164]=0.69, p)$ $0.05)$.

The fifteenth null hypothesis stated that there would be no significant difference between the students and teachers on the Irreversibility of Suicide Subscale. Since there was no significant difference, this null hypothesis is accepted.

The sixteenth null hypothesis stated that there would be no significant difference between type of schools on the Irreversibility of Suicide Subscale. Since there was no significant difference, the sixteenth null hypothesis is accepted.

Demographic Aspects: The mean performances of the groups on the Demographic Aspects of Suicide are presented in Table 21. Table 22 contains the analysis of variance for this subscale. As is seen on this table, there was a significant difference between the students and teachers on this subscale $(F[1,164)=9.55, p<0.005)$. However, there was no significant difference between the types 
Table 19

\begin{abstract}
Means on the Irreversibility of Suicide
Subscale for the Students and Teachers

and for the Types of Schools
\end{abstract}

Types of Schools

Public

Private

$\begin{array}{llcc}\text { Roles } & & \text { AVERAGE } \\ \text { Students } & 14.56 & 14.96 & 14.66 \\ \text { Teachers } & 14.73 & 15.89 & 14.90 \\ \text { AVERAGE } & 14.63 & 15.19 & \end{array}$

Table 20
Analysis of Variance for the Irreversibility
8
of Suicide Subscale Comparing Roles
and Types of Schools

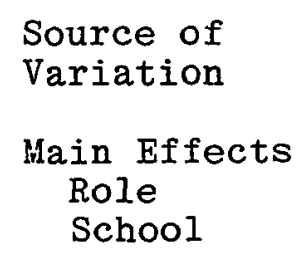

2-way Interaction

Explained

Residual

Total

\begin{tabular}{rrrr}
$\begin{array}{l}\text { Sum of } \\
\text { Squares }\end{array}$ & $\mathrm{df}$ & $\begin{array}{l}\text { Mean } \\
\text { Square }\end{array}$ & \multicolumn{1}{c}{$\mathrm{F}$} \\
\hline 12.76 & 2 & 6.38 & 1.40 \\
3.61 & 1 & 3.61 & 0.79 \\
10.56 & 1 & 10.56 & 2.32 \\
3.15 & 1 & 3.15 & 0.69 \\
15.92 & 3 & 5.30 & 1.16 \\
745.57 & 164 & 4.54 & \\
761.50 & 167 & 4.56 &
\end{tabular}


Table 21

Means on the Demographic Aspects of Suicide

Subtest for the Students and Teachers

and for the Types of Schools

Types of Schools

Public Private

Roles

AVERAGE

Students

7.85

8.14

7.93

Teachers

8.98

8.56

8.92

AVERAGE

8.30

8.24

Table 22

Analysis of Variance for the Demographic

Aspects of Suicide Subtest Comparing

the Roles and Types of Schools

Source of

Variation
Main Effects
Role
School

2-way Interaction

Explained

Residual

Total

$*_{p}<0.01$

$* * p<0.005$

\begin{tabular}{|c|c|c|c|}
\hline $\begin{array}{l}\text { Sum of } \\
\text { Squares }\end{array}$ & $d f$ & $\begin{array}{l}\text { Mean } \\
\text { Square }\end{array}$ & $\mathrm{F}$ \\
\hline $\begin{array}{r}38.57 \\
38.49 \\
0.28\end{array}$ & $\begin{array}{l}2 \\
1 \\
1\end{array}$ & $\begin{array}{r}19.28 \\
38.49 \\
0.28\end{array}$ & $\begin{array}{l}4.78 * \\
9.55 * * \\
0.07\end{array}$ \\
\hline 2.90 & 1 & 2.90 & 0.71 \\
\hline 41.47 & 3 & 13.82 & 3.43 \\
\hline 660.80 & 164 & 4.02 & \\
\hline 702.28 & 167 & 4.20 & \\
\hline
\end{tabular}


of schools $(F[1,164]=0.07, p>0.05)$ nor was there a significant interaction $(F[1,164]=0.72)$.

Examination of the means for students and teachers shows that the students scored significantly lower (mean $=$ 7.93) than the teachers (mean $=8.92$ ). Since there was a significant difference between the students and teachers, the fifteenth null hypothesis, which focused on these differences, is rejected. The fact that there was no significant difference between the types of schools results in the acceptance of the sixteenth null hypothesis.

Aging and Suicide: The performances of the groups on the Aging and Suicide Subscale appear in Table 23. Table 24 presents the analysis of variance for this subscale. As is reflected in this table, there was no significant difference between students and teachers $(F[1,165]=$ $0.422, p>0.05)$ or between types of schools ( $F[1,165]$ $=0.03, p>0.05)$. Nor was there a significant interaction $(F[1,165]=0.18)$.

The eighteenth null hypothesis stated that there would be no significant difference between teachers and students on the Aging and Suicide Subscale. Since there was no significant difference between these groups, the eighteenth null hypothesis is accepted.

The nineteenth null hypothesis stated that there would be no significant difference between the types of 
Table 23

\begin{abstract}
Means on the Aging and Suicide Subscale
for the Students and Teachers and

for the Types of Schools
\end{abstract}

Types of Schools

Public Private

$\begin{array}{rrrr}\text { Roles } & & \text { AVERAGE } \\ \text { Students } & 11.90 & 11.75 & 11.86 \\ \text { Teachers } & 12.04 & 12.22 & 12.07 \\ \text { AVERAGE } & 11.95 & 11.86 & \end{array}$

Table 24

Analysis of Variance for the Aging

and Suicide Subscale Comparing

the Roles and Types of Schools

\begin{tabular}{|c|c|c|c|c|}
\hline $\begin{array}{l}\text { Source of } \\
\text { Variation }\end{array}$ & $\begin{array}{l}\text { Sum of } \\
\text { Squares }\end{array}$ & $\mathrm{df}$ & $\begin{array}{l}\text { Mean } \\
\text { Square }\end{array}$ & $\underline{F}$ \\
\hline $\begin{array}{l}\text { Main Effects } \\
\text { Role } \\
\text { School }\end{array}$ & $\begin{array}{l}1.73 \\
1.49 \\
0.10\end{array}$ & $\begin{array}{l}2 \\
1 \\
1\end{array}$ & $\begin{array}{l}0.86 \\
1.49 \\
0.10\end{array}$ & $\begin{array}{l}0.24 \\
0.42 \\
0.03\end{array}$ \\
\hline 2-way Interaction & 0.62 & 1 & 0.62 & 0.17 \\
\hline Explained & 2.35 & 3 & 0.78 & 0.22 \\
\hline Residual & 585.92 & 165 & 3.55 & \\
\hline Total & 588.28 & 168 & 3.50 & \\
\hline
\end{tabular}

Reproduced with permission of the copyright owner. Further reproduction prohibited without permission. 
schools on their performance on the Aging and Suicide Subscale. Since there was no significant difference between the types of schools, the nineteenth null hypothesis is accepted.

Motivation for Suicide: The means for the groups on the Motivation for Suicide Subscale are shown in Table 25. Table 26 presents the analysis of variance for this data. As is illustrated in this table, there was no significant difference between students and teachers on this subscale $(F[1,162]=0.25, p>0.05)$. There was also no significant difference between the types of schools $(F[1,162]=1.01, p>0.05)$ nor was the interaction term significant $(F[1,162]=0.11, p>0.05)$.

The twenty-first null hypothesis stated that there would be no significant difference between students and teachers on the Motivation for Suicide Subscale. Since there is no significant difference between students and teachers on this subscale, the twenty-first hypothesis is accepted.

The twenty-second null hypothesis stated that there would be no significant difference between types of schools on the Motivation for Suicide Subscale. Since there is no significant difference between the types, this hypothesis is accepted. 
Table 25

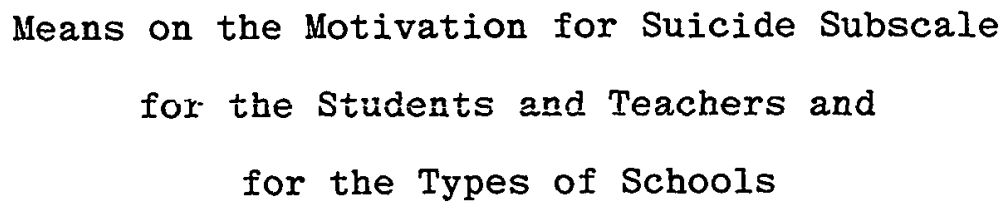

Table 26

Analysis of Variance for the Motivation

for Suicide Subtest Comparing

the Roles and Types of Schools

Source of
Variation
Main Effects
Role
School
2-way Interaction
Explained
Residual
Total

\begin{tabular}{rrrr}
$\begin{array}{l}\text { Sum of } \\
\text { Squares }\end{array}$ & df & $\begin{array}{l}\text { Mean } \\
\text { Square }\end{array}$ & $F$ \\
\hline 6.80 & 2 & 3.40 & 0.71 \\
1.19 & 1 & 1.19 & 0.25 \\
4.85 & 1 & 4.85 & 1.01 \\
0.53 & 1 & 0.53 & 0.11 \\
7.34 & 3 & 2.44 & 0.51 \\
774.77 & 162 & 4.78 & \\
782.12 & 165 & 4.74 &
\end{tabular}


Impulsivity and Suicide: The average performances of the four groups on the Impulsivity and Suicide Subscale appear in Table 27. The analysis of variance for this subscale is presented in Table 28. This table reflects that there was no significant difference between the students and teachers $(F[1,165]=0.12, p>0.05)$. There was also no significant difference between the types of schools $(F[1,165]=3.18, p>0.05)$. However, there was a significant interaction of roles and types of schools $(F[1,165]=5.15, \mathrm{p}(0.03)$.

However, since there was a significant interaction of roles and types, a test of simple main effects was computed. The results of this test also appear in Table 28 . As is reflected in this table, there was a significant difference between the public and private students (Schools at $R(S), F[1,165]=7.30, p(0.01)$. By looking at the means, it can be seen that the public students (mean $=3.44$ ) were significantly lower than the private school students $($ mean $=10.36)$.

The twenty-third null hypothesis stated that there would be no significant difference between students and teachers on the Impulsivity Subscale. Since there was no significant difference between these two groups, this null hypothesis is accepted.

The twenty-fourth null hypothesis stated that there would be no significant difference between the types of 
Table 27

\begin{abstract}
Means for the Impulsivity and Suicide
Subscale for the Students and Teachers

and for the Types of Schools
\end{abstract}

Types of Schools

Public Private

Roles

AVERAGE

Students

9.44

10.36

9.68

Teachers

9.79

9.22

9.70

AVERAGE

9.58

10.08

schools on this subscale. Since there was no significant difference between the two types, this hypothesis is accepted.

Getting Even: The mean performances on the Getting Even Subscale are seen in Table 29. The analysis of variance for this subtest is contained in Table 30. This table reflects that there was no significant difference between the students and teachers on this subscale $(F[1,164]=2.95, p>0.05)$. There was no significant difference between the types of schools $(F[1,164]=0.01$, p > 0.05) nor was there a significant interaction $(F[1,164]=0.03)$.

The twenty-fifth null hypothesis stated that there 
Table 28

$$
\begin{aligned}
& \text { Analysis of Variance for the Impulsivity } \\
& \text { and Suicide Subscale Comparing the } \\
& \text { Roles and Types of Schools with } \\
& \text { Simple Main Effects Comparisons }
\end{aligned}
$$

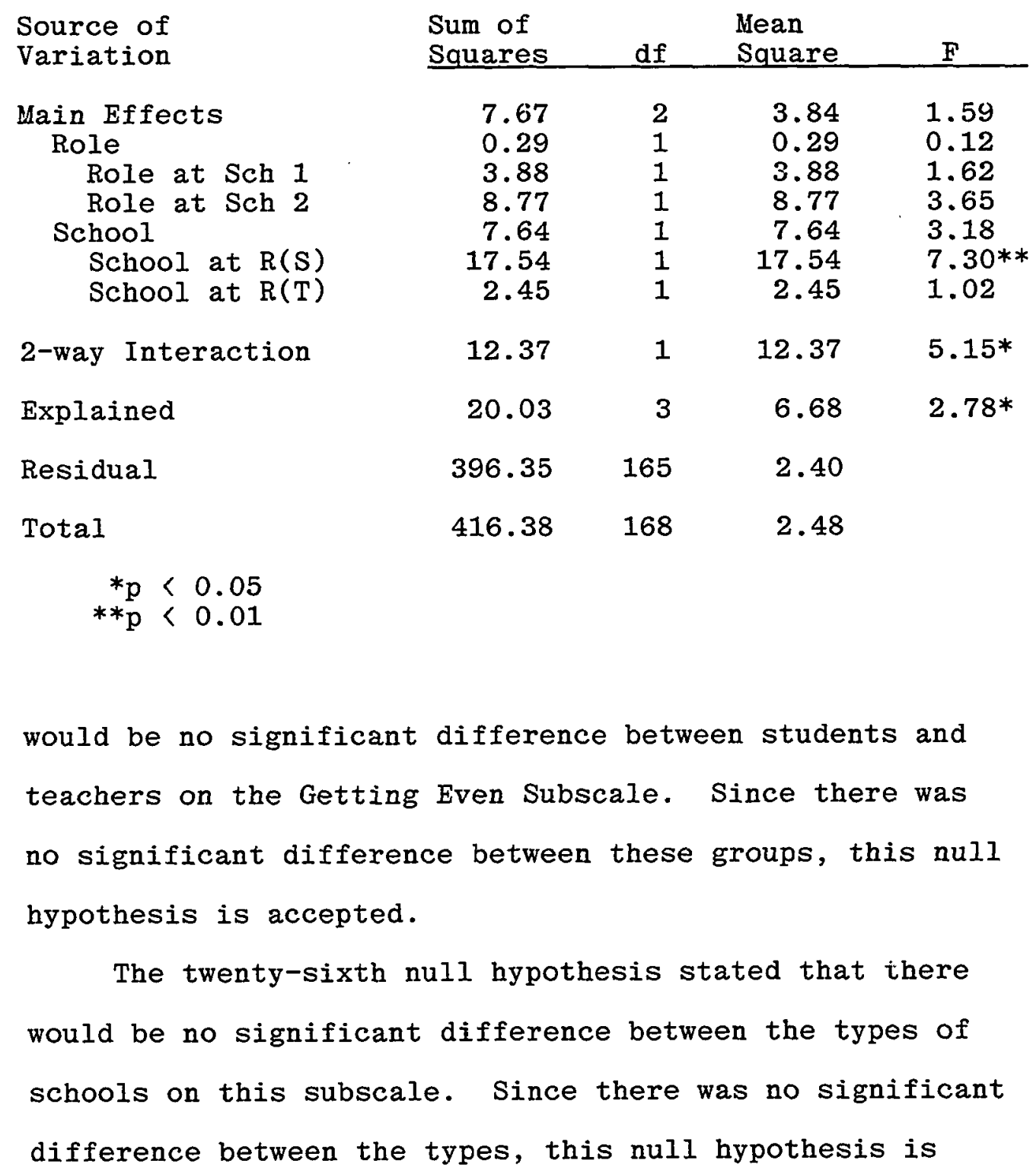


Table 29

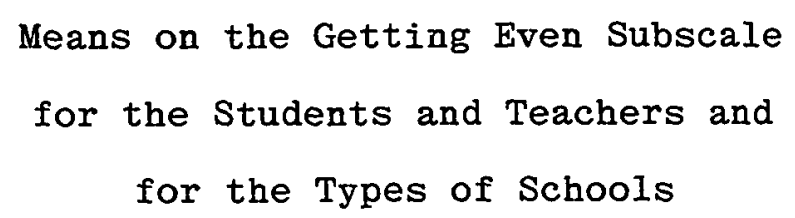

Roles

AVERAGE

$\begin{array}{cccc}\text { Students } & 8.41 & 8.50 & 8.43 \\ \text { Teachers } & 9.08 & 9.00 & 9.07 \\ \text { AVERAGE } & 8.67 & 8.62 & \end{array}$

\author{
Table 30 \\ Analysis of Variance for the \\ Getting Even Subscale Comparing \\ Roles and Types of Schools
}

Source of
Variation
Main Effects
Role
School
2-way Interaction
Explained
Residual
Total

Source of

Variation
lain Effects
Role

2-way Interaction

\begin{tabular}{rrrr}
$\begin{array}{l}\text { Sum of } \\
\text { Squares }\end{array}$ & df & $\begin{array}{l}\text { Mean } \\
\text { Square }\end{array}$ & \multicolumn{1}{c}{$F$} \\
\hline 15.76 & 2 & 7.88 & 1.48 \\
15.69 & 1 & 15.69 & 2.95 \\
0.06 & 1 & 0.06 & 0.01 \\
0.16 & 1 & 0.16 & 0.03 \\
15.93 & 3 & 5.31 & 0.99 \\
871.73 & 164 & 5.31 & \\
887.66 & 167 & 5.31 &
\end{tabular}


accepted.

Individual Aspects of Suicide: The mean performances of the four groups appear in Table 31 . Table 32 presents the analysis of variance for the Individual Aspects of Suicide Subscale. As is shown in this table, there was a significant difference between the students and teachers on this subscale $(F[1,163]=7.29, p<0.01)$. There was no significant difference between types of schools $(F[1,163]=0.008, p>0.05)$ nor was there a significant interaction $(F[1,163]=0.56, p>0.05)$.

The twenty-seventh null hypothesis stated that there would be no significant difference between students and teachers in terms of their scores on the Individual Aspects Subscale. As stated before, there was a significant difference. Therefore, the twenty-seventh null hypothesis is rejected. Examination of the group means indicates that the students scored significantly higher (mean = 9.74) than the teachers (mean $=9.02)$ on this subtest. The twenty-eighth null hypothesis stated that there would be no significant difference between the types of schools on the Individual Aspects Subtest. Since there was no significant difference between the two types of schools, the twenty-eighth null hypothesis is accepted.

Sensation Seeking Attitudes of Sujcide: The means 
Table 31

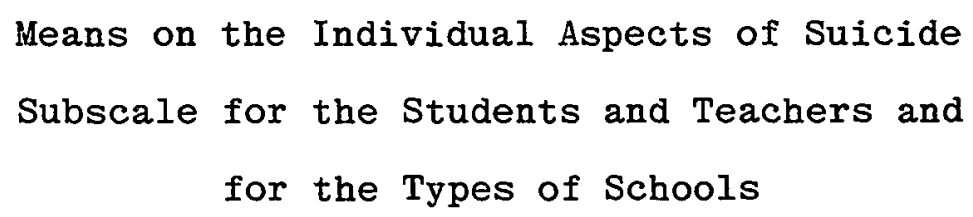

AVERAGE

9.46

9.54

Table 32

$$
\begin{gathered}
\text { Analysis of Variance for the Individual } \\
\text { Aspects Subscale Scores Comparing } \\
\text { Roles and Types of Schools }
\end{gathered}
$$

\begin{tabular}{|c|c|c|c|c|}
\hline $\begin{array}{l}\text { Source of } \\
\text { Variation }\end{array}$ & $\begin{array}{l}\text { Sum of } \\
\text { Squares }\end{array}$ & $d f$ & $\begin{array}{l}\text { Mean } \\
\text { Square }\end{array}$ & F \\
\hline $\begin{array}{l}\text { Main Effects } \\
\text { Role } \\
\text { School }\end{array}$ & $\begin{array}{r}20.04 \\
19.86 \\
0.02\end{array}$ & $\begin{array}{l}2 \\
1 \\
1\end{array}$ & $\begin{array}{r}10.02 \\
19.86 \\
0.02\end{array}$ & $\begin{array}{l}3.67^{*} \\
7.29 * * \\
0.01\end{array}$ \\
\hline 2-way Interaction & 1.53 & 1 & 1.53 & 0.56 \\
\hline Explained & 21.57 & 3 & 7.19 & 2.64 \\
\hline Residual & 444.09 & 163 & 2.72 & \\
\hline Total & 465.67 & 166 & 2.80 & \\
\hline
\end{tabular}


scores for the four groups on the Sensation Seeking Subscale are presented in Table 33. The analysis of variance for this subscale is shown in Table 34. As can be seen in this table, there was a significant difference between students and teachers on this subscale $(F[1,163]=9.37$, $p(0.005)$. However, there was no significant difference between the types of schools $(F[1,163]=0.15, p>0.05)$ nor was there a significant interaction $(F[1,163]=0.28$, $\mathrm{p}>0.05$ ).

The twenty-ninth null hypothesis stated that there would be no significant difference between students and teachers in their performances on the Sensation Seeking Attitudes Subscale. Since there was a significant difference between the groups, this null hypothesis is rejected. On this area, the mean performance of the students (mean $=10.28$ ) was significantly higher than that of the teachers (mean $=9.42)$.

The thirtieth null hypothesis stated that there would be no significant difference between the types of schools on the Sensation Seeking Subtest. Since there was no significant difference between the groups, the thirtieth null hypothesis is accepted.

\section{Related Analyses}

Several various aspects were addressed in this section. The first analysis was for the score which represented 
Table 33

\begin{abstract}
Means on the Sensation Seeking Attitudes
Subscale for the Students and Teachers

and for the Types of Schools
\end{abstract}

Types of Schools

Public Private

$\begin{array}{lrrr}\text { Roles } & & \text { AVERAGE } \\ \text { Students } & 10.34 & 10.11 & 10.28 \\ \text { Teachers } & 9.39 & 9.56 & 9.42 \\ \text { AVERAGE } & 9.97 & 9.97 & \end{array}$

Table 34

Analysis of Variance for the Sensation

Seeking Attitudes Subscale Comparing

Roles and Types of Schools

\begin{tabular}{|c|c|c|c|c|}
\hline $\begin{array}{l}\text { Source of } \\
\text { Variation }\end{array}$ & $\begin{array}{l}\text { Sum of } \\
\text { Squares }\end{array}$ & df & $\begin{array}{l}\text { Mean } \\
\text { Square }\end{array}$ & $\underline{F}$ \\
\hline $\begin{array}{l}\text { Main Effects } \\
\text { Role } \\
\text { School }\end{array}$ & $\begin{array}{r}29.13 \\
29.13 \\
0.45\end{array}$ & $\begin{array}{l}2 \\
1 \\
1\end{array}$ & $\begin{array}{r}14.56 \\
29.13 \\
0.45\end{array}$ & $\begin{array}{l}4.68^{*} \\
9.37^{* *} \\
0.14\end{array}$ \\
\hline 2-way Interaction & 0.88 & 1 & 0.88 & 0.28 \\
\hline Explained & 30.02 & 3 & 10.00 & $3.21 * *$ \\
\hline Residual & 506.83 & 163 & 3.10 & \\
\hline Total & 536.85 & 166 & 3.23 & \\
\hline
\end{tabular}


the attitude of the individual toward suicide. The mean performances for the groups for Attitude Toward Suicide Subscale are shown in Table 35. The analysis of variance for this general subscale appears in Table 36 . As is reflected in this table, there was a significant difference between students and teachers in their attitudes ( $F[1,147]$ $=19.22, p(0.001)$. Further, there was no significant difference between the types of schools $(F[1,147]=0.96$, p > 0.05) nor was there a significant interaction $(F[1,147]=1.57, p>0.05)$.

By looking at the means for the two groups, it can be discerned that the students (mean $=139.92)$ scored lower than the teachers (147.23). The significant difference indicates that the students' mean was significantiy lower than the teachers' mean.

The next analysis examined the performances of the groups on the subtest that reflected the knowledge about suicide. The means on the Knowledge Subscale are presented in Table 37. The analysis of this subtest is seen in Table 38. As is illustrated by this table, there was a significant difference between students and teachers in knowledge score $(F[1,154]=14.85, p<0.001)$. Further, there was no significant difference between the types of schools $(F[1,154]=1.96, p>0.05)$ nor was there a significant interaction $(F[1,154]=0.09, p>0.05)$. The mean of the students (mean $=113.15)$ was lower 
Table 35

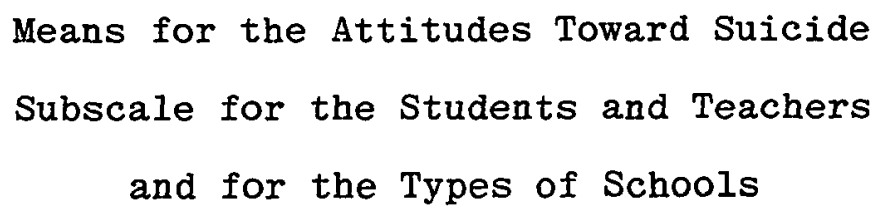

Roles

Students

Teachers

AVERAGE

$\begin{array}{lc}136.24 & 135.67 \\ 148.67 & 140.33 \\ 140.89 & 136.83 \\ & \\ \text { Table } 36 & \\ \text { Variance for the Attitudes } \\ \text { uicide Subscale Comparing } \\ \text { and Types of Schools }\end{array}$

Analysis of Variance for the Attitudes

Toward Suicide Subscale Comparing

Roles and Types of Schools

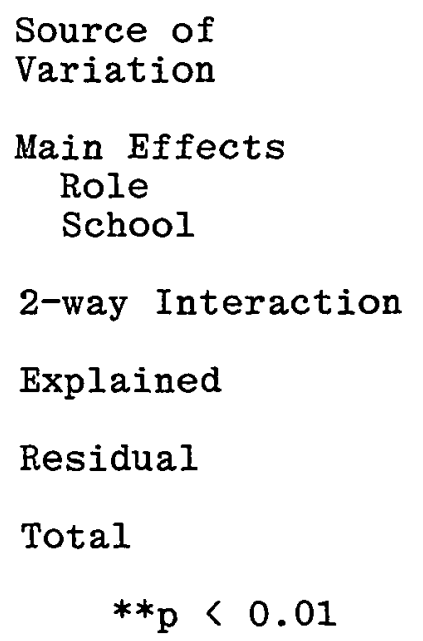

Source of
Variation
Main Effects
$\quad$ Role
School
2-way Interaction
Explained
Residual
Total
$\quad * *$ p 0.01

\begin{tabular}{|c|c|c|c|}
\hline $\begin{array}{l}\text { Sum of } \\
\text { Squares }\end{array}$ & $d f$ & $\begin{array}{l}\text { Mean } \\
\text { Square }\end{array}$ & $\underline{F}$ \\
\hline $\begin{array}{r}4436.65 \\
3986.14 \\
198.19\end{array}$ & $\begin{array}{l}2 \\
1 \\
1\end{array}$ & $\begin{array}{r}2218.32 \\
3986.14 \\
198.19\end{array}$ & $\begin{array}{c}10.69 * * \\
19.21 * * \\
0.95\end{array}$ \\
\hline 325.96 & 1 & 325.96 & 1.57 \\
\hline 4762.61 & 3 & 1587.53 & $7.65 * *$ \\
\hline 30494.42 & 147 & 207.44 & \\
\hline 35257.04 & 150 & 235.04 & \\
\hline
\end{tabular}


Table 37

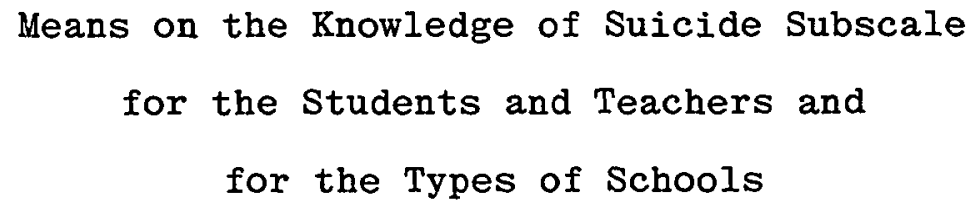

Table 38

Analysis of Variance for the Knowledge of Suicide Subscale Comparing Roles and Types of Schools

\begin{tabular}{|c|c|c|c|c|}
\hline $\begin{array}{l}\text { Source of } \\
\text { Variation }\end{array}$ & $\begin{array}{l}\text { Sum of } \\
\text { Squares }\end{array}$ & $d f$ & $\begin{array}{l}\text { Mean } \\
\text { Square }\end{array}$ & $\underline{\mathbf{F}}$ \\
\hline $\begin{array}{l}\text { Main Effects } \\
\text { Role } \\
\text { School }\end{array}$ & $\begin{array}{r}714.47 \\
677.46 \\
89.59\end{array}$ & $\begin{array}{l}2 \\
1 \\
1\end{array}$ & $\begin{array}{r}357.23 \\
677.46 \\
89.59\end{array}$ & $\begin{array}{c}7.83^{* *} \\
14.85^{* *} \\
1.96\end{array}$ \\
\hline 2-way Interaction & 4.10 & 1 & 4.10 & 0.09 \\
\hline Explained & 718.58 & 3 & 239.52 & $5.25 *$ \\
\hline Residual & 7024.64 & 154 & 45.61 & \\
\hline Total & 7743.22 & 157 & 49.32 & \\
\hline
\end{tabular}


than that of the teachers (mean $=117.28$ ). Since there was a significant difference between the students and teachers, it can be inferred that the students scored significantly lower than the teachers.

\section{$\underline{\text { Summary }}$}

This chapter has presented the results of the data analyses. The chapter began with an overview of the demographic variables. After these analyses, the analyses of the fifteen subscales of the "Suicide Opinion Questionnaire" were completed. After each analysis, the appropriate null hypothesis was rejected or accepted.

Of the thirty null hypotheses advanced, eleven were rejected. Of these eleven, ten reflected significant differences between student and teacher on one of the subscales. Further, when the overall scales of Attitude Toward Suicide and Knowledge of Suicide were analyzed, the significant difference between students and teachers once again emerged.

The next chapter reviews the study and examines these results. From this examination, conclusions are made and then discussed. The fifth chapter ends with recommendations for future studies. 


\section{Chapter 5}

Summary, Conclusions, and Recommendations

Chapter 5 is divided into five sections. The first section examines the purpose of the study along with an abbreviated review of the literature and states the purpose of the study. The second section addresses conclusions regarding the objectives and hypotheses. The third section discusses the implications of the findings. The fourth section identifies recommendations for future research, and the last section offers a summary of the research.

\section{Summary of the Purpose of the Study and Review of the}

\section{Literature}

The purpose of this study was to compare the attitude and knowledge of suicide of high school students with the attitude and knowledge of suicide of high school teachers. This study examined the following:

1. The attitude and knowledge of high school teachers and high school students on issues related to the acceptability and normality of suicide.

2. The attitude and knowledge of high school teachers and high school students on issues related to suicide 
and mental and moral illness.

3. The attitude and knowledge of high school teachers and high school students on issues related to suicide as semi-serious.

4. The attitude and knowledge of high school teachers and high school students on issues related to suicide and religion.

5. The attitude and knowledge of high school teachers and high school students on issues related to suicide and the risk of suicide.

6. The attitude and knowledge of high school teachers and high school students on issues related to suicide and the lethality of suicide.

7. The attitude and knowledge of high school teachers and high school students on issues related to suicide and the normality of suicide.

8. The attitude and knowledge of high school teachers and high school students on issues related to suicide and irreversibility of suicide.

9. The attitude and knowledge of high school teachers and high school students on issues related to suicide and demographic aspects.

10. The attitude and knowledge of high school teachers and high school students on issues related to suicide and aging.

11. The attitude and knowledge of high school teachers 
and high school students on issues related to suicide and motivation.

12. The attitude and knowledge of high school teachers and high school students on issues related to suicide and impulsivity.

13. The attitude and knowledge of high school teachers and high school students on issues related to suicide and getting even.

14. The attitude and knowledge of high school teachers and high school students on issues related to suicide and individual aspects.

15. The attitude and knowledge of high school teachers and high school students on issues related to suicide and sensation-seeking.

In addition, the study includea a demographic investigation which contributed to a further examination of data which directly reflected information about the sample population participating in this study.

Chapter 2 presented a brief history of suicide from the earliest incident thought to be suicidal to the present. It attempted also to investigate the motive for suicide and theories attempting to explain the incident of adolescent suicide. Finally, the chapter discussed unresolved issues, significant problems, and unanswered questions about adolescent suicide.

With respect to the research on adolescent suicide, 
there does not exist a great extent of material on the subject. Most research, except research conducted by Charlotte Ross in San Mateo, California, fails to involve high school students directly. This research reflects a new investigation into the actual sample population affected by adolescent suicide. Both high school students and high school teachers were involved in this research for the purpose of possibly developing prevention and intervention suicide programs for high school students.

\section{Conclusions Regarding Objectives and Hypotheses}

The objectives of this research were met in that the researcher succeeded in establishing a greater understanding of both high school students and high school teachers on attitudes and knowledge on issues related to suicide. In addition, the time lines were met, and this fact kept the research within a timeframe consistent with the research plan. Lastly, the objective was met which assumed that the high school districts and respective staffs and students would participate in this research study. This accomplishment represents the most important component of this section.

In regard to the hypotheses, of the thirty hypotheses, eleven were rejected and ten of these were between students and teachers. In order to enhance the interpretation of these findings, each subsection which reflects 
a significant difference will be identified in addition to the number of the questions from the "Suicide Opinion Questionnaire" which correspond to the subsection.

Subsection Reflecting Significant Difference Population

Questions from

Normality of Suicide

$\begin{array}{ll}\begin{array}{l}\text { Students and Teachers } \\ \text { Private and Public }\end{array} & 18,25,49,70,85 \\ \text { Students } & 50,57,9,95 \\ \text { Students and Teachers } & \begin{array}{l}97,80,68,55, \\ 78,87,19\end{array} \\ & 56,54,52,38 \\ \text { Students and Teachers } & \\ & 72,64,24,41 \\ \text { Students and Teachers } & \\ \begin{array}{l}\text { Students and Teachers } \\ \text { Students and Teachers }\end{array} & 3,51,15 \\ \begin{array}{l}\text { Public and Private } \\ \text { Students }\end{array} & 10,14,24 \\ \text { Students and Teachers } & 90,45,89\end{array}$

Individual Aspects

The table above represents the findings of the research in relationship to the subsections and the questions from the S. O. Q. which are present in each subsection. Out of 15 categories, there appears to be a significant difference between the sample populations in seven of the subsections. The sample populations included students and teachers from public and private high schools. The researcher did a cross tabulation between the two groups. The discussion below identifies only the cross tabulations 
which were significant.

\section{Normality of Suicide:}

High school students agree more than high school teachers, and private high school students agree more than public high school students:

1. Suicide is an acceptable means to end an incurable illness.

2. Suicide is acceptable for aged and infirm persons.

3. There may be situations where the only reasonable solution is suicide.

4. If someone wants to commit suicide, it is his business and we should not interiere.

5. Potentially, every one of us can be a suicide victim.

6. In general, suicide is an evil act not to be condoned.

7. People do not have the right to take their own lives.

These statements reflect a very significant attitude of high school students and students attending a private high school, in particular. This finding indicates a need to further investigate the matter of high school students and their feelings about suicide and the normality of the act. For example, the fact that the students feel that there are situations where the only reasonable solution 
is suicide is significant. Why is it that students feel that suicide is a solution at all? What is it that provokes an attitude among our young people that suicide is a solution? Even though the students feel that suicide is not to be condoned, their attitude is that intervention is inappropriate. This attitude needs to be addressed and investigated. It is very frightening to this researcher that students agree more than teachers that suicide is an acceptable means to any situation. The fact that they feel that an intervention is perhaps inappropriate is even more alarming. If 6,000 adolescents are killing themselves each year and the projected number of incidences is on the increase, we must begin to offer both educational and counseling support services to our young people. To ignore this data, and to accept these findings with no response, is to neglect our responsibility to the young people of our nation.

\section{Hental and Moral Illness:}

High school students agree more than high school teachers:

1. Suicide is a very serious moral transgression.

2. Suicide goes against the laws of God and/or of nature.

3. Suicide among young people (e.g., college students) is particularly puzzling, since they have everything to 
live for.

4. Those people who attempt suicide are usually trying to get sympathy from others.

5. People who die by suicide should not be buried in the same cemetery as those who die naturally.

6. Those who commit suicide are cowards who cannot face life's challenges.

These findings indicate a need to discuss the motivation of suicide with students. Some of the above comments are very strong in their implications. For example, that suicide is a moral transgression and that suicide is an attempt to get sympathy from others, are feelings about suicide with very little empathy. Perhaps a discussion of these statements and issues related to these statements would promote a greater understanding of the incident and a greater sensitivity to prevention and intervention programs. The fact that students feel that a suicide attempt is an attempt to get sympathy and not a real "cry for help" is concerning to this researcher. Attempts to educate students on the seriousness of the suicide attempt are crucial to this issue.

\section{Suicide as Semi-serious:}

High school students agree more than high school teachers: 
1. Once a person survives a suicide attempt, the possibility of his trying again is minimal.

2. Improvement following a suicidal crisis indicates that the risk is over.

3. Prisoners in jail who attempt suicide are simply trying to get better living conditions.

4. People who commit suicide must have a weak personality structure.

This finding is again significant as it relates to the lack of knowledge that students have about the incidence of suicide and its relationship to attempts. In addition, these results reflect a lack of information on the part of the high school students about the reoccurrence of suicide attempts. It is imperative to educate high school students on issues related to this subsection. If, for example, a student knows of another student who has attempted suicide and believes that one attempt will not lead to another, then, of course, this posture does away with the need in the mind of the student for intervention. In fact, the opposite is true, and there is a very good chance that once a person has attempted suicide he will, in fact, try again. These results further support the need for education and training of our youth on issues related to suicide. 
Risk of Suicide:

High school students agree more than high school teachers:

1. A large percentage of suicide victims come from broken homes.

2. A person whose parent has committed suicide is a greater risk for suicide.

3. Obese individuals are more likely to commit suicide than persons of normal weight.

4. John Doe, age 45 , has just committed suicide. An investigation will probably reveal that he has considered suicide for quite a few years.

The results of this subsection investigation reveal a greater understanding of the students on these statements. These findings indicate a need for teachers to be educated on the risk of suicide and those individuals who might attempt suicide. It is true, for example, that a person whose parent has committed suicide is a greater risk for suicide. This subsection does not reflect critical issues and concerns but it does include statements which should be discussed in the educational framework of the topic of suicide.

Demographic Aspects:

High school students agree more than high school teachers: 
1. The suicide rate is higher for blacks than for whites.

2. Suicide is more prevalent among the very rich and the very poor.

3. The suicide rate is higher for minority groups such as Chicanos, Ameican Indians, and Puerto Ricans than for whites.

This finding indicates a need to educate high school students about the population of suicide attempters and victims. In fact, the highest rate of suicide is among white males. In addition, the majority of attempters do not come from very rich or very poor homes, but they come from middle income families. It is also important to offer education to young people on this issue concerning demographic aspects because they need to know how frequently suicide attempters do come from the white male population. This knowledge will perhaps alert the young adolescents to the fact that suicide victims who offered clues to suicide attempts should have been taken seriously, thus further emphasizing the need for prevention and intervention practices.

\section{Impulsivity:}

High school students agree more than high school teachers, and public high school students agree more than 
private high school students:

1. Most suicide attempts are impulsive in nature.

2. Those who threaten to commit suicide rarely do so.

This finding is very significant. High school students must be educated to the fact that individuals who threaten to commit suicide often do so. The fact that public high school students are less informed on this issue is also significant. These results further emphasize the need for curriculum and education in the area of suicide and identifying prodromal clues.

Individual Aspects:

High school students agree more than high school teachers:

1. Most people who commit suicide do not believe in an afterlife.

2. Children from larger families (i.e., three or more children) are less likely to commit suicide as adults than single or only children.

3. Suicide attempters are, as individuals, more rigid and less flexible than non-attempters.

These findings introduce some very interesting attitudes on the part of the high school students. The issue of suicide and a belief in an afterlife is an 
interesting discussion item. More important, it offers an opportunity for discussion which, in turn, leads to further discussion on other issues related to suicide. The primary purpose of exploring the above statements is not in arriving at an absolute solution, but in discussing issues related to suicide with the hope of arriving at prevention and intervention strategies. It is also an attempt to get at the motives and attitudes of suicide attempters with the hope of understanding them and their motive for suicide.

I have attempted to list, in detail, the results of the research project in an effort to specifically identify attitudes and issues concerning suicide. It was very surprising to this researcher that the population most in need of education and training was the student population. The most significant concern on the part of this researcher is in the area of the normality and acceptability of suicide. It is both alarming and frightening to find that high school students find that suicide may be a reasonable solution in some situations. It is also of considerable concern that high school students are seemingly unaware that suicide attempts and warnings should be taken seriously and that they seem to have little empathy for the suicide victim or attempter. As an educator and a mother of two teenagers, I am committed to pursue this topic and introduce into the high school curriculum the topic of suicide 
and the facts surrounding the incidence of suicide. Until we face the issue and begin to educate our young people on this very crucial and deadly movement, we cannot begin to practice responsible intervention and prevention practices. If we fail to address this movement and this horrifying increase in adolescent suicide, then we fail our children and we lose our most valuable possession, our young people.

In addition to the aforementioned data, it is interesting to note from the research that the students scored lower than the teachers on the knowledge questions related to suicide. However, there was no significant difference between students from public high schools and private high schools on knowledge, but overall scores on attitude were lower for public high school students than for private high school students.

Also, this researcher has succeeded in drawing more attention to this topic of great significance, and because of this research, this researcher has encouraged other individuals to pursue this area of interest. Lastly, and most important, this research project will serve as a useful tool in assisting in the development of meaningful suicide intervention and prevention programs for adolescents.

\section{Implications of Findings}

Since large numbers of 15 to 24 year olds are students, 
Seiden (1984) reminds us that the academic environment has received its share of scrutiny as a possible influence on the rising tide of youthful suicides. He observes: When the postwar baby boom generation reached college age, large numbers of youngsters were forced to compete for an adequate number of academic slots. This resulted in fierce competition for admission to college, and continuing pressures after acceptance . . . Many of the students who killed themselves were onedimensional personalities. Almost all of their success and all of their energies were tied up in academic achievement to the exclusion of social outlets. Nonetheless, they were rarely pleased with their academic performances, although many had had high grades and excellent scholarship. No matter how well they did it was not good enough. (p.3)

Galle (1972) reports that various studies on the incidence of adolescent suicide reveal some interesting data regarding the environments of the suicidal adolescents. Previous studies of population density and human behavior have indicated a relationship between high population density/overcrowding and crime or social unrest (p.23). Seiden (1984) adds, "but certain social problems such as alcohol abuse and suicide flourish in low-density 
environments (p.2). Seiden indicates that new evidence indicates that paradoxically, under certain circumstances "undercrowding" and isolation may also play a significant role in some youthful suicides. He also states that suicide among 15 to 24 year olds is most prevalent in the western United States, particularly in intermountain regions--in areas of extremely low population densities (p.3).

Even though the findings of this research registered a significant difference in attitudes and knowledge of suicide between the two populations, O'Roark (1982) reminds us of this important fact:

The teenager who has reached the point of seriously considering suicide never fails to send out warning signals. Parents, teachers, relatives, caregivers, and others must realize that these prodromal clues are a sign that help is needed. These prodromal clues are warning signals to potential suicidal behavior; they are a "cry for help." (p.22)

Tishler (1981) suggests that while not all people with behavioral changes become suicidal, the majority of suicide attempters have evidenced some of the following behavioral changes (p.98):

1. A drastic change in personal appearance, particularly from good to bad.

2. Somatic complaints, such as muscle aches and 
pains, stomach aches, backaches, diarrhea, headaches, or constipation.

3. Inability to concentrate.

4. Problems in judgment and memory.

5. A dramatic shift in the quality and quantity of school work.

6. Changes in daily behavior and living patterns such as extreme fatigue, boredom, altered sleep patterns, and decreased or increased appetite.

7. Social and school change, including disruptive behavior in a classroom situation, falling asleep in class, or inability to sit still.

8. Emotional outbursts (often compounded with laughing or crying) or sudden bursts of energy followed by lethargy.

9. Excessive use of alcohol or drugs.

10. Signs of mental illness such as delusions or hallucinations.

11. Loss of friends.

12. An overwhelming sense of guilt or shame.

13. Talking of suicide or writing a last will and testament. (It is a myth that people who talk of suicide will not really kill themselves. Most suicide completers tell someone before they act.)

Tishler also reports that life situations that seem relatively unimportant to adults could present a crisis to 
the adolescent. These could include:

1. Death of a family member, close friend, or relative.

2. Divorce or separation of parents, relatives, or close friends.

3. Difficulty with the law (self or family).

4. Injury or chronic illness.

5. Marriage of a sibling or remarriage of parents.

6. Being fired from a job or parent being fired.

7. Retirement of parents.

8. A change in health of a close family member or friend.

9. Pregnancy, abortion, or birth of a baby (to self, girlfriend, parent, sibling, or friend).

10. A drastic change for the better or worse in the family's financial status (business failures, successes, foreclosures).

11. A sibling or close friend leaving home for camp or college.

12. Superior or poor achievement.

13. Mother beginning or stopping a work career.

14. Beginning or ending of high school.

15. Change in residence, school, or friends.

16. Death of a pet.

17. Trouble with a teacher or employer, or parent having trouble with an employer. 
18. Special times, such as vacations, holidays, or the first week of spring.

19. The anniversary of parents' divorce or death of a loved one or a holiday recalling a lost parent.

Jacobziner (1965) suggests that school curriculum could be of help in preventing suicide. Sartore (1976) suggests that school curriculum should contain information about suicide. He suggests that students need information on causes, symptoms, and alternatives to suicide. He comments, "The likelihood of suicide can be minimized through an educational program which emphasizes understanding rather than avoidance" ( $p .339)$.

Berg (1972) reflects the same feelings and suggests that the discussion of suicide in the classroom can serve to help adolescents understand how their emotions influence their behavior and serve to lessen feelings of isolation when students learn their peers have similar problems. He states that in a school setting, three different points of intervention are possible:

1. The teacher may intervene directly with the student. The teacher may confront the student and let him know that the teacher realizes there is a problem. The first step toward solving the problem is creating an awareness.

2. The second possible point of intervention is 
with the student's family. Berg believes that the teacher should not tell the family that the student may be suicidal but, rather, should simply point out that a major change has been noticed in the classroom.

3. Another person should be made aware of the student's problem. Berg feels that it is important that the student be put in contact with someone to whom he or she can talk openly about feelings. He recommends that the school administrators establish good relationships with those outside the school setting where help can be obtained. He suggests that school administrators can be very influential in creating an environment that projects a positive influence toward dealing with emotional problems.

Powers (1979) addresses the situation where a student makes a suicide threat or conveys some idea of selfdestruction to a teacher. Powers suggests the following:

1. The teacher should listen carefully to what the student says. The teacher should show concern and interest and should try to help.

2. A suicide threat should aIways be taken seriously-and not be considered a manipulative effort--even though there may be some manipulation taking place.

3. The teacher will have to decide the degree of urgency. Powers suggests that although the adolescent may not wish that this information be shared with parents, the teacher is responsible for doing so if it is determined 
that the parents should be informed.

4. The teacher and the school can be of help to the parents and adolescent by assisting them in obtaining the help of a professional.

5. Powers points out that if help for the student is not available outside the school, the teacher can be of assistance by mobilizing help and a support system within the school; this would include the school counselor, other teachers, and selected students.

Fisher (1973) reports that suicidologists readily acknowledge that the school as an institution offers one of our greatest preventive potentials, and suggests that it should serve as one of the foremost defenses against self-destructive behavior (p.208). She reflects that it is school personnel whose close and extended exposure to young people places them in a unique position to identify the early stages of crisis and enables them to intervene by offering adult support and guidance at the most strategic time (p.208).

Hafen (1972) states that teachers are among the everyday people in a person's life who make up the front line of defense against suicide. They are the people, he suggests, who can offer the most immediate help in a suicidal crisis (p.84). Farberow (1957) reminds us that teachers ought not to add the role of therapist to their already overburdened repertoire. Rather, they should 
be able to recognize an adolescent who is having emotional difficulty and to take some responsibility for ensuring that the youngster is referred to an appropriate person (p.32). Fisher supports this statement:

Recognizing that intervention is simply the course of action open to anyone faced with the problem of a student suicide, the documented intervention technique readily available to teachers is that of allowing troubled youth to open their hearts and tell what is troubling them . . . the amount is not as important as the presence of a compassionate listener who will permit them to express feelings such as anger and resentment. (p.73) Jacobs (1971), in his studies with survivors of suicide attempts, advocates the development of programs designed to increase and extend interaction between troubled students and their peers and teachers which increases the potential for establishing meaningful interactions. Ross (1980), who is an advocate of creating programs for high schools, reported that the Suicide Prevention and Crisis Center of San Mateo County, California, conducted a pilot project in one high school district (six schools) and one community college, and included workshops, training courses, and in-class presentations at the high school and college levels. As a result of this experiment, the 
Center received an increase in requests for consultation with school personnel in their own management of suicidal patients. Prior to the presentations, the more frequent requests were for direct counseling services following a suicide attempt. As a result of a thorough training program, the schools took a greater responsibility for intervention, but used the Center as a significant authority for consultation.

In summary, some of the implications from the findings have been identified and school personnel should become involved in the process of identifying students who exemplify certain prodromal clues, receive training in this area, and begin to work with each other and outside agencies in developing an educational curricular program and active intervention program for students who need intervention and assistance.

The researcher recommends that the following be adhered to by teachers who work with adolescents, as suggested by Davis $(1983: 72,73)$ :

1. Learn the prodromal clues of suicide.

2. If an adolescent exhibits any of these prodromal clues, allow yourself to believe that the adolescent may be suicidal.

3. In either instance, talk freely, calmly, and directly with the adolescent about these feelings. Ask questions about how long the adolescent has felt this 
way, whether the adolescent has a suicide plan, whether the adolescent has acquired the means, etc. No judgmental remarks should be made and the adolescent should not be reassured that "everything is OK." Do not get involved with any argument about life versus death. Listen carefully to what the adolescent says and try to understand what the adolescent is feeling. Remember that as a general rule, the more specific the suicidal plan, the higher the risk. Also remember that suicidal individuals are generally very honest about their feelings and intentions.

4. Get professional help for the adolescent regardless of any denial of intent to commit suicide. If the adolescent is in any immediate danger, do not leave the adolescent alone.

5. DO SOMETHING.

In conclusion, Allen (1976) reminds us that public education cannot change attitudes overnight. Suicide prevention needs to be planned as a long-range process that eventually will result in the reduction of suicide taboo and enable people to receive, accept, and act on the practical wisdom that can save many from untimely deaths. She remarks:

Large scale mass education such as we have been used to the past three years--employing television broadcasting, radio, newspapers, magazines, 
posters, and brochures--cannot be expected to have instant effects on a large portion of the population. This takes repetition and time. There is a need for increased efforts in creating a suicide prevention awareness at all levels-individual, community, state, and national. The time is ripe. (p.200)

She speaks to the issue of program planning and education (1976:196):

1. Appraising educational resources available and planning for additional resources to meet program needs.

2. Utilizing baseline data about suicide prevention attitudes, knowledge, and practices.

3. Defining and setting short-range, intermediate, and long-range educational objectives within a specific suicide prevention program.

4. Planning and executing educational activities to implement suicide preventional program goals.

5. Recognizing and dealing with social, psychological, and cultural factors relating to the understanding and acceptance of suicide prevention practices.

These recommendations are appropriate for addressing the issue of developing a suicide prevention and intervention program and should be considered by high school communities who wish to commit to this worthwhile endeavor. 
Recommendations for Further Research:

The issue of adolescent suicide needs to be researched in the future. Particular attention should be paid to the following:

1. Future research should address the differences in attitudes of high school teachers and high school students on issues related to suicide.

2. Future research should examine the issue of significant differences between the attitude and knowledge of public and private high school students on issues related to suicide and impulsivity.

3. Future research should examine the issue of the significant differences between the attitude and knowledge of public and private high school students on issues related to suicide and the normality and acceptability of suicide.

4. Future research should examine the effects of Suicide Prevention Centers on the rate of the number of referrals to Suicide Prevention Centers as a result of teacher training prevention and intervention programs.

5. Future research should examine the issue of teacher and student in-service programs which address the issue of suicide prevention and intervention programs.

\section{Summary}

This research has provided information which further enhances the understanding of the attitudes and knowledge 
of both high school teachers and high school students on issues related to suicide. It has successfully addressed the hypotheses and included within its framework appropriate information on the review of the literature and significant implications resuiting from the findings of this research project. 


\section{References}

Allen, N. H. (1976). The health educator as a suicidologist. Suicide and Iife-threatening behavior, $\underline{6}, 195-201$.

Alvarez, A. (1972). The savage god: A study of suicide.

New York: Bantam Books.

Berg, D. E. (1972). A plan for preventing student suicide. Self-destructive behavior: A national crisis. Burgess. Corder, B. F., W. Shorr, and R. Corder (1972). Chological characteristics of adolescent suicide. Adolescence, $\underline{9}, 1-6$.

Davis, Patricia (1983). Suicidal adolescents. Illinois: Charles C. Thomas Publisher.

Domino, G., D. Moore, L. Westlake, and L. Gibson (1982). Attitudes towards suicide: A factor analytic approach. Journal of clinical psychology, 38, 257, 262.

Farberow, N. L. (1957). Clues to suicide. New York: McGraw Hill Book Co., Inc.

Farberow, N. (1977). Adolescent suicide. Proceedings from the 9 th international congress for suicide prevention: Helsinki.

Farberow, N. L. (1983). Adolescent suicide. The adolescent and mood disturbance. New York: International Universities Press. 
Farberow, N. L. (1961). Summary. In Normal Le. Farberow (Ed.), The cry for help. New York: McCraw Hill. Farberow, N. L. (1975). Cultural history of suicide. In Normal L. Farberow (Ed.), Suicide in different cultures. Baltimore: University Park Press, 1975. Farberow, N. I. (1983). Suicide update. Advance in psychology. Villanova, Proscientia.

Fisher, S. A. (1973). Suicide and crisis intervention. New York: Springer Publishing Co., Inc. Frederick, C. (1976). Trends in mental health: Self destructive behavior among younger age groups. Rockville, MD: Department of Health, Education, and Welfare, Pub. no. (ADM) 76-365.

Galle, O. R. and J. M. Miller (1972). Population, density and pathology: What are the relations for man? Science, $1972, \underline{176}, 23-30$.

Hafen, B. Q. and E. J. Faux (1972). Self-destructive behavior: A national crisis. Minneapolis, Minnesota: Burgess Publishing Co.

Hatton, C. L., S. Valente, and McBride (1977). Suicide and Assessment and Intervention. New York: AppletonCentury Crosts.

Jacobs, J. (1971). Adolescent suicide. New York: John Wiley and Sons, Inc. Jacobziner, H. (1965). Attempted suicides in adolescents by poisonings: Statistical report. American journal 
Kovacs, M., A. T. Beck, and A. Weissman (April, 1974). Hopelessness: A powerful predictor of suicidal behavior. Paper presented at a meeting of the American Association of Suicidology, Jacksonville, Florida.

McIntire, M. S. and C. R. Angle (1971). Suicide as seen in poison control centers. Pediatrics, $48,914$. McIntire, M. S. (1975). Suicide and self poisoning in pediatrics. Advanced pediatric, 24, 291-309.

McKenry, Patrick, Ph.D., C. L. Tishler, and C. Kelley (1982). Adolescent suicide. Clinical pediatrics, $\underline{5}$, 266-270.

Miller, J. P. (1975). Suicide and adolescence. Adolescence, 10, 11-24.

Motto, J. (April 16, 1982). Development of a suicide risk assessment instrument. Paper read at 15 th annual meeting of the American Association of Suicidology. New York: New York.

O'Roark, Mary Ann (1982). The alarming rise in teenage suicide. McCalls, $1,14-22$.

Peck, M. (October, 1967). Some characteristics of adolescent suicide in Los Angeles. Paper presented at a symposium on suicide, San Francisco.

Peck, M. L. (1981). Teenage suicide--a tragic impulse. MD, 49-52.

Peck, M. I. (1982). Youth suicide: The role of school consultation. Unpublished paper. 
Peck, M. L., N. L. Farberow, and R. E. Litman (1985). Youth suicide. New York: Springer Publishing Company. Powers, Douglas (1979). The teacher and the adolescent suicide threat. The journal of school health, 10, 561563 .

Ross, C. P. (1980). Mobilizjng schools for suicide prevention. Suicide and life threatening behavior, 10, 239-243.

Ross, C. P. (1984). Group counseling for suicidal adolescents. Suicide in the young. London, wright PSG.

Schrut, A. (1964). Suicidal adolescents and children. Journal American medical association, 188, 1103-1107. Schrut, A. and T. Michaels (1969). Adolescent girls who attempt suicide: Comments on treatment. Americall journal of psychotherapy, 23, 243-251.

Seiden, R. H. (at press). Death in the west. Western journal of medicine.

Seiden, R. H. (1984). The youthful suicide epidemic. Public affairs report, $25,1,3$.

Seiden, R. H. (1974). Studies of adolescent suicidal behavior. Perspectives in abnormal behavior. New York: Pergamon.

Seiden, R. H. and R. P. Freitas (1980). Shifting patterns of deadly violence. Suicide and life threatening behavior, 10, 195-209. 
Teicher, J. D. and J. Jacobs (1966). Adolescents who attempt suicide: Preliminary findings. American journal psychiatry, 122, 1248.

Tishler, C. L., P. C. McKenry, and K. C. Morgan (1981). Adolescent suicide attempts: Some significant factors. Suicide Iife threatening behavior, $11,31$.

Tishier, C. L., P. C. McKenry, and K. C. Morgan (1981). Adolescent suicide attempts: Some significant factors. Suicide and life threatening behavior, $\underline{2}, 92$.

Tishler, C., P. McKenry, and K. Morgan (1981). Adolescent suicide attempts: Some significant factors. Suicide life threatening behavior, $11,86-92$.

U. S. vital statistics 1974 and 1975: Volume II--mortality-Washington, D. C.: National Center for Health Statistics, 1978 .

Vital statistics of the United States (1979). Washington, D. C.: U. S. Department of Health and Human Services, Public Health Service.

Williams, C. and C. M. Lyons. Family interaction and adolescent suicidal behavior: A preliminary investigation. American. 
APPENDIX A

LETTER TO SUPERINTENDENTS

Reproduced with permission of the copyright owner. Further reproduction prohibited without permission. 
October 10, 1985

\section{Dear Superintendent:}

As per our phone conversation I am providing you with background information and a proposal for my dissertation. Presentiy I am enrolled at the University of San Diego and I am formulating my dissertation proposal. In order to proceed with my project, I am requesting permission to include the students and staff of your high school site as the subjects for my dissertation.

The rate of suicide has increased alarmingly during the past two decades. Among young people between the ages of fifteen and twenty-four, the incidence has skyrocketed. With the impact of the rising suicide rate among youth and the publicity attendant to it, there has been a rising interest in introducing suicide prevention programs in the high school arena. Senate Bill 947, approved by the Governor September 12, 1983, provided for the development of a youth suicide prevention school program, by adding Chapter 3 to Part 7 of the Education Code, commencing with Section 10200 .

Eoucation Code Section 10200 states that a "statewide youth suicide prevention program is essential in order to address the continuing problem of youth suicide throughout the state." This program emphasizes a partnership between educational programs at the state and local levels and community suicide prevention and crisis center agencies.

In response to this mandate, it would appear to me that it is very important, prior to the implementation of suicide prevention programs, that information is gathered in order to determine the baseline attitude and knowledge of the participants in the intervention programs. It seems apparent to me that we cannot assume certain needs for intervention programs without first establishing both commonalities and differences between students and the individuals posing the interventions. Therefore, I would like to administer the attached "Suicide Opinion Questionnaire" (SOQ) to approximately thirty of your high school students (with parent permission, of course) and thirty of your high school teachers with the hopes of establishing both the attitudes and knowledge of both populations regarding the issue of suicide. This data can then be 
utilized to more responsibly address this critical issue.

I am prepared to present my dissertation proposal to your school board in order to gain support for my efforts.

Sincerely,

Karen Clark

Principal

James Dukes Elementary School 
APPENDIX B

LETTER TO PARENTS

Reproduced with permission of the copyright owner. Further reproduction prohibited without permission. 
Dear Parents,

I am presently enrolled in a doctoral program at the University of San Diego. In addressing the subject of my dissertation, I know that as an educator I wish to conduct my research in an area which is vital to educational research. As a parent, however, I wish to make a meaningful contribution to our youth.

It is my intent to investigate a very serious issue regardins adolescents. I am currently conducting an investigation into the issue of suicide and more specifically, adolescent suicide. Due to current legislation and the backing of many prominent educators, there exists a movement toward the prevention and intervention of adolescent suicide. What is missing however, is the research and data which provide a solid indicator of the attitude and knowledge of both educators and students regarding this issue.

Therefore, I would like permission for your child to participate in responding to a survey instrument which will measure attitude and knowledge of suicide. What I hope to derive from this study is information which can be used for both prevention and intervention programs specifically designed for students on this issue. Both high school students and teachers will be surveyed, and the results will be utilized to enhance current suicide prevention and intervention programs. Your child may withdraw from the study whenever he/she wishes to do so.

I wish to thank the high school and the high school district for supporting me in this endeavor.

Please sign the attached form and return it with your child to school. Thank you for your support for such a worthwhile cause.

Sincerely,

Karen Clark, Principal James Dukes Elementary School

Doctoral Student, University of San Diego

My child has permission to complete the "Suicide Opinion Questionnaire" (SOQ).

Student's name

Parent's Signature 
APPENDIX C

"SUICIDE OPINION QUESTIONNAIRE"

Reproduced with permission of the copyright owner. Further reproduction prohibited without permission. 
SUICIDE OPINION QUESTIONNAIRE

This is not a test, but a survey of your opinions; there are no right or wrong answers, only your honest opinion counts.

For each item, indicate (on the answer sheet; whether you: $\underline{A}$. strongly agree B. agree $\underline{C}$. are undecicied D. disagree E. strongly disagree

1. Most persons who attempt suicide are lonely and depressed.

2. Almost everyone has at one time or another thought about suicide.

3. The suicide rate is higher for blacks than for whites.

4. The actual suicide rate in the U. S. is much greater than reflected by official statistics.

5. Suicide prevention centers actually infringe on a person's right to take his life.

6. Most suicides are triggered by arguments with a spouse.

7. The higher incidence of suicide is due to the lesser influence of religion.

8. Many suicide notes reveal substantial anger toward the world.

9. I would feel ashamed if a member of my family committed suicide.

10. Most suicide attempts are impulsive in nature.

11. Many suicides are the result of the desire of the victim to "get even" with someone.

12. In the U.S. suicide by shooting oneself is the most common method.

13. People with incurable diseases should be allowed to commit suicide in a dignified manner.

14. Those who threaten to commit suicide rarely do so. 
For each item, indicate (on the answer sheet) whether you: A. strongly agree $B$. agree $C$. are undecided $D$. disagres E. Strongly disagree

15. Suicide is more prevalent among the very rich and the very poor.

16. Individuals who kill themselves out of patriotism do so, not because they are courageous, but because they enjoy taking major risks.

17. Suicide is a leading cause of death in the U. S.

18. Suicide is an acceptable means to end an incurable illness.

19. People who commit suicide are usually mentally ill.

20. Some people commit suicide as an act of selfpunishment.

21. The feeling of despair reflected in the act of suicide is contrary to the teachings of most major religions.

22. Suicide rates vary greatly from country to country.

23. I feel sorry for people who commit suicide.

24. John Doe, age 45 , has just committed suicide. An investigation will probably reveal that he has considered suicide for quite a few years.

25. Suicide is acceptable for aged and infirm persons.

26. The suicide rate among physicians is substantially greater than for other occupational groups.

27. The Japarese Kamikaze pilots who destroyed themselves by flying their airplanes into a ship should not be considered suicide victims.

28. Different cultural child-rearing practices are probably unrelated to suicide rates.

29. Suicide is clear evidence that man has a basically aggressive and destructive nature.

30. Over the past ten years the suicide rate in this country has increased greatly. 
For each item, indicate (on the answer sheet) whether you: $A$. strongly agree $B$. agree $C$. are undecided $D$. disagree E. strongly disagree

31. Most people who try to kill themselves don't really want to die.

32. Suicide happens without warning.

33. A business executive arrested for fraud or other illegal practices should face punishment like a man rather than seek suicide as an escape.

34. Most suicide victims are older persons with little to live for.

35. A person who tried to commit suicide is not really responsible for those actions.

36. About $75 \%$ of those who successfuliy conmit suicide have attempted suicide at least once before.

37. It is rare for someone who is thinking about suicide to be dissuaded by a "friendly ear."

38. People who commit suicide must have a weak personality structure.

39. The method used in a given suicide probably reflects whether the action was impulsive or carefully and rationally planned.

40. Social variables such as overcrowding and increased noise can lead a person to be more suicide-prone.

41. A large percentage of suicide victims come from broken homes.

42. A rather frequent message in suicide notes is one of unreturned love.

43. People who set themselves on fire to call attention to some political or religious issue are mentally unbalanced.

44. The possibility of committing suicide is greater for older people (those 60 and over) than for younger people $(20$ to 30$)$.

45. Most people who commit suicide do not believe in an afterlife. 
For each item, inoiicate (on the answer sheet) whether you: $\underline{A}$. strongly agree B. agree $C$. are undecided $D$. disagree E. strongly disagree

46. In times of war, for a captured soldier to commit suicide is an act of heroism.

47. Suicide attempters are typically trying to get even with someone.

48. Once a person is suicidal, he is suicidal forever.

49. There may be situations where the only reasonable solution is suicide.

50. People should be prevented from committing suicide since most are not acting rationally at the time.

51. The suicide rate is higher for minority groups such as Chicanos, American Indians, and Puerto Ricans than for whites.

52. Improvement following a suicidal crisis indicates that the risk is over.

53. People who engage in dangerous sports like automobile racing probably have an unconscious wish to die.

54. Prisoners in jail who attempt suicide are simply trying to get better living conditions.

55. Suicide among young people (e.g., college students) is particularly puzzling since they have everything to live for.

56. Once a person survives a suicide attempt, the probability of his trying again is minimal.

57. In general, suicide is an evil act not to be condoned.

58. People who attempt suicide and live should be required to undertake therapy to understand their inner motivation.

59. Suicide is a normal behavior.

60. Many victims of fatal automobile accidents are actually unconsciously motivated to commit suicide. 
For each item, indicate (on the answer sheet) whether you: $\underline{A}$. strongly agree $B$. agree $\bar{c}$. are undecided $\underline{D}$. disagree E. strongly disagree

61. If a culture were to allow the open expression of feeijngs like anger and shame, the suicide rate would decrease substantially.

62. From an evolutionary point of view, suicide is a natural means by which the less mentally fit are eliminated.

63. Suicide attempters who use public places (such as a bridge or tall building) are more interested in getting attention.

64. A person whose parent has committed suicide is a greater risk for suicide.

65. External factors, like lack of money, are a major reason for suicide.

66. Suicide rates are a good indicator of the stability of a nation; that is, the more suicides the more problems a nation is facing.

67. Sometimes suicide is the only escape from life's problems.

68. Suicide is a very serious moral transgression.

69. Some individuals have committed suicide to preserve their honor; these were victims of cultural values rather than disturbed personal attitudes.

70. If someone wants to commit suicide, it is their business and we should not interfere.

71. A suicide attempt is essentially a "cry for help."

72. Obese individuals are more likely to commit suicide than persons of normal weight.

73. Heroic suicides (e.g., the soldier in war throwing himself on a live grenade) should be viewed differently from other suicides (e.g., jumping off a bridge).

74. The most frequent message in suicide notes is of loneliness. 
For each item, indicate (on the answer sheet) whether you: A. strongly agree B. agree $\underline{C}$. are undecided $\underline{D}$. disagree E. strongly disagree

75. Usually, relatives of a suicide victim had no idea of what was about to happen.

76. Long-term self-destructive behaviors, such as alcoholism, may represent unconscious suicide attempts.

77. Suicide attempts are typically preceded by feelings that life is no longer worth living.

78. Suicide goes against the laws of God and/or of nature.

79. We should have "suicide clinics" where people who want to die could do so in a painless and private. manner.

80. Those people who attempt suicide are usually trying to get sympathy from others.

81. People who commit suicide lack solid religious convictions.

82. People with no roots or family ties are more likely to attempt suicide.

83. People who bungle suicide attempts really did not intend to die in the first place.

84. Passive suicide, such as an overdose of sleeping pills, is more acceptable than violent suicide such as by gunshot.

85. Potentially, every one of us can be a suicide victim.

86. Suicide occurs only in civilized countries.

87. People who die by suicide should not be buried in the same cemetery as those who die naturally.

88. Most people who commit suicide do not believe in God.

89. Children from larger families (i.e., three or more children) are less likely to commit suicide as adults than single or only children.

90. Suicide attempters are, as individuals, more rigid and less flexible than non-attempters. 
For each item, indicate (on the answer sheet) whether you: $\underline{A}$. Strongly agree $\underline{B}$. asree $C$. are undecided $\underline{D}$. disagree E. strongly disagree

91. The large majority of suicide attempts result in death.

92. Some people are better off dead.

93. People who attempt suicide are, as a group, less religious.

94. As a group: people who commit suicide experienced disturbed family relationships when they were young.

95. People do not have the right to take their own lives.

96. Most people who attempt suicide fail in their attempts.

97. Those who commit suicide are cowards who cannot face life's challenges.

98. Individuals who are depressed are more likely to commit suicide.

99. Suicide is much more frequent in our world today than it was in early cultures such as Egypt, Greece, and the Roman Empire.

100. People who are high suicide risks can be easily identified.

101. Are you a student or a teacher?
A. student
B. teacher

102. Are you male or female?
A. male
B. female

103. If you are a student, what grade level are you at?
A. freshman
B. sophomore
C. junior
D. senior 
104. If you are a student, what grades do you mostly get?
A. Mostly A's
B. Mostly B's
C. Mostly C:s
D. Mostly D's
E. Mostly F's

105. If you are a teacher, how old are you?
A. $\quad 20-30$
B. $30-40$
C. $40-50$
D. $50-60$
E. $60-70$

106. If you are a teacher, what do you teach?
A. English / Reading
B. Math / Science
C. Language
D. Social Studies / History
E. Other 